\title{
LAS SANCIONES DEL CONSEJO DE SEGURIDAD DE LAS NACIONES UNIDAS Y LOS DERECHOS HUMANOS. RELACIONES PELIGROSAS
}

\author{
Virginia GALLO COBIÁN* \\ Ximena GAUCHÉ MARCHETTI** \\ María José HUERTAS JIMÉNEZ***
}

RESUMEN: El presente trabajo colectivo tiene por eje central el análisis de las medidas del Consejo de Seguridad de Naciones que no implican uso de la fuerza, conocidas usualmente como sanciones internacionales, y que se insertan en el gran propósito de la Organización de velar por el mantenimiento de la paz y la seguridad internacionales, y sus relaciones con la protección de los derechos humanos. El estudio se completa con el análisis de la jurisprudencia del Tribunal de Primera Instancia de las Comunidades Europeas que ha servido de ejemplo paradigmático de afectación de garantías y libertades fundamentales a partir de las medidas que adopta el Consejo de Seguridad.

ABSTRACT: The focal point of this collective article is to examine those measures not involving the use of armed force imposed by the Security Council, usually known as international sanctions, which fall within the main purpose of the United Nations, namely the maintenance of international peace and security, as well as to analyze their connection with the protection of human rights. This study is completed by the analysis of the jurisprudence of the Court of First Instance of the European Communities, which served as a paradigmatic example of how those measures adopted by the Security Council may affect the fundamental freedoms and guarantees of individuals.

RÉSUMÉ: Le présent travail collectif a pour axe central l'analyse des mésures du Conseil de Sécurité des Nations Unies qui n'impliquent pas l'usage de la force, plus connues comme sanctions internationales et qui s'insèrent dans le grand but de l'Organisation de veiller au maintien de la paix et la sécurité internationales, et ses relations avec la protection des droits de l'homme. Complète cette étude l'analyse de la jurisprudence du Tribunal de première instance des Communautés Européennes, qui a servit d'exemple paradigmatique d'endommagement aux garanties et libertés fondamentales à partir des mesures adoptées par le Conseil de Sécurité.

* Doctoranda en derecho internacional y relaciones internacionales en el Instituto Universitario de Investigación "Ortega y Gasset".

** Profesora asistente de Derecho internacional y derechos humanos en la Facultad de Ciencias Jurídicas y Sociales de la Universidad de Concepción, en Chile, y doctoranda en derecho internacional y relaciones internacionales en el Instituto Universitario de Investigación "Ortega y Gasset".

*** Doctoranda en derecho internacional y relaciones internacionales en el Instituto Universitario de Investigación "Ortega y Gasset”. 
SUMARIO: I. Introducción. II. Las sanciones internacionales en el marco de las propuestas de reforma de las Naciones Unidas. III. Sanciones internacionales y vulneración de derechos humanos. Análisis jurisprudencial en el ámbito del TJCE.

IV. Conclusiones.

\section{INTRODUCCIÓN}

Más de seis décadas después de la aprobación de la Carta de las Naciones Unidas (CNU) todavía nos preguntamos si ésta será finalmente un instrumento eficaz para alcanzar la tan ansiada paz entre todos los pueblos de la Tierra. El llamado sistema de seguridad colectiva que se establece en el capítulo VII de la Carta pretende configurar el marco adecuado que debía convertir nuestro planeta en un lugar seguro y pacífico. Con este fin, el mantenimiento de la paz fue considerada la tarea primordial del Consejo de Seguridad (CSNU), órgano al que corresponde el control del uso de la fuerza y cuya virtud consiste en intervenir en aquellas situaciones en que la paz y la seguridad mundiales se vean amenazadas. ${ }^{1}$ Cuando concurre una amenaza en este sentido el Consejo debe optar entre usar la fuerza, autorizar su uso o adoptar medidas correctoras de esta situación que no impliquen el uso de la misma.

Con arreglo a esta lógica de actuación, las llamadas sanciones internacionales o sanciones multilaterales ${ }^{2}$ están desempeñando un rol fundamental y han sido objeto de estudios, críticas y alabanzas, pues hoy constituyen el campo principal en que se mueve el CSNU.

En los hechos, entre 1990 y 2002 se han aplicado, de una manera u otra, sanciones en los casos de Irak, Libia, la ex Yugoslavia, la actual Yugoslavia, Haití, Somalia, Angola, Rwanda, Liberia, Sudán, Sierra

1 Huelga recordar que en el sistema concebido en la Carta de Naciones Unidas sólo se admiten dos excepciones al principio del no uso de la fuerza: la legítima defensa, con las condiciones que establece el artículo 51 de la Carta, y las medidas que puede adoptar el CSNU, y que implican el uso de la fuerza, conforme a los artículos 42 y ss.

2 Es importante la calificación de multilaterales, puesto que es hoy una práctica extendida entre los Estados, la imposición de medidas bilaterales, usualmente llamadas también sanciones. Ejemplo clásico de ellas son las impuestas a Cuba por los Estados Unidos desde hace décadas y, más recientemente, las impuestas por el Japón a Corte del Norte por su prueba nuclear de fines de 2006. 
Leona, Camboya, Afganistán, Eritrea y Etiopía. ${ }^{3}$ En los años posteriores también han sido destinatarios de estas medidas establecidas por el Consejo de Seguridad la República Democrática del Congo, Costa de Marfil, Sudán, Corea del Norte y, más recientemente y como consecuencia de la actualidad por todos conocida, Irán. ${ }^{4}$ Desde 2006, el tema de las sanciones ha experimentado un considerable renacer a partir de la controversia internacional generada por la prueba nuclear norcoreana de 9 octubre de 2006 y el juego de poder que se ha visto principalmente entre los Estados Unidos, desde su posición a todas luces evidente de control del Consejo, y el régimen de Pyongyang, y por el desarrollo del programa nuclear iraní que también está teñido de intereses básicamente estatales.

Sea como fuere, es indudable, y así se tratará de reflejar en nuestra exposición, que las sanciones han cambiado desde la década de los noventa a estos días, y hoy se habla con bastante propiedad por Naciones Unidas de la aplicación de sanciones inteligentes o selectivas para diferenciarlas de las primeras que fueron adoptadas en el marco de su actuación.

En efecto, la llegada del anterior secretario general, el ghanés Kofi Annan, trajo nuevos bríos a la organización, pues se dedicó, no sin críticas por cierto, a solicitar y realizar una serie de informes sobre diversas cuestiones propias del funcionamiento de las NU, entre las cuales las sanciones tuvieron un papel relevante. ${ }^{5}$

A lo largo del presente trabajo nos dedicaremos a analizar este tipo de medidas como forma de actuación del CSNU y sus relaciones con los derechos humanos, por estimar que éste es el punto más peligroso de las consecuencias prácticas que puede acarrear el uso de las mismas en el marco del mantenimiento de la paz y la seguridad internacionales.

3 Craven, M., "Humanitarianism and the Quest for Smarter Sanctions", European Journal of International Law, vol. 13, núm.1, 2002, p. 44.

4 Si bien se hará referencia más adelante a la situación actual de las sanciones impuestas a algunos de estos países, especialmente a los dos últimos, Corea del Norte e Irán, valga como anticipo recordar el vínculo electrónico (en español) de la página web de Naciones Unidas en el que se recogen de manera sistemática y expositiva, siendo asimismo de fácil acceso, la variada serie de documentos relacionados con la materia: http://www.un.org/spanish/sc/committees/.

5 Durante su tiempo, se han introducido nuevos conceptos, por ejemplo, la llamada "responsabilidad de proteger", y nuevas ideas para mejorar los mecanismos existentes de NU para trabajar en ámbitos como la erradicación de la pobreza o el mantenimiento de la paz, por señalar los que estimamos más relevantes. 
Para lograr este objetivo vamos a comenzar con un estudio doctrinal del concepto y los elementos de las sanciones, tratando también las distinciones entre las llamadas sanciones globales y las sanciones selectivas o inteligentes, que constituyen la situación actual y que han ocasionado, al parecer, más polémicas que beneficios tangibles.

En el mismo orden de ideas, realizaremos a continuación un análisis comparativo del tratamiento que se viene dando a las sanciones en el marco del proceso de reforma del sistema onusiano, proceso que se impulsa desde distintos sectores y que busca mejorar su "base legal". Este análisis se hará a partir de algunos de los principales documentos en los que se plasma el actual proceso de reformas a Naciones Unidas y una de las más recientes resoluciones del Consejo de Seguridad, la 1730, de 19 de diciembre de 2006, en la que se ponen las bases para mejorar el sistema de sanciones en los términos que se analizarán después.

Puesto que una de las mayores controversias que generan las sanciones es su posible incompatibilidad con muchos de los derechos fundamentales de las personas sobre quienes pueden recaer, la parte siguiente hará un estudio de las relaciones entre las sanciones y los derechos humanos. Esto se hará sobre la base del análisis jurisprudencial de sentencias dictadas por el Tribunal de Primera Instancia de las Comunidades Europeas y sobre la práctica de las Naciones Unidas, que muestran además los estrechos y a veces difíciles vínculos que existen entre el derecho internacional, marco jurídico en que se mueve el Consejo de Seguridad, y el derecho comunitario, marco de actuación de las instituciones de la Unión Europea. ${ }^{6}$

Finalizamos con un apartado de conclusiones en que reflejamos nuestras ideas globales sobre la cuestión objeto del trabajo.

6 Sobre este tema, en especial, véase los epígrafes II y III del interesante trabajo de Roldán, J., "La justicia comunitaria y el control de legalidad de las resoluciones del Consejo de Seguridad de Naciones Unidas. Comentario a las sentencias Yusuf/Al Barakaat y Kadi, de 21 de septiembre de 2005, del Tribunal de Primera Instancia de las Comunidades Europeas", Revista Española de Derecho Internacional, vol. LVII, núm. 2, 2005, pp. 873-878. 


\section{LAS SANCIONES INTERNACIONALES EN EL MARCO DE LAS PROPUESTAS DE REFORMA DE LAS NACIONES UNIDAS ${ }^{7}$}

\section{Aproximación al concepto de sanciones internacionales}

Para conseguir su principal propósito, la Carta de las Naciones Unidas ha creado un sistema de seguridad colectiva, recogido en el capítulo VII, que es administrado de manera centralizada por el Consejo de Seguridad, en cuanto órgano principal de la organización según el artículo 7o. de la Carta. En aras de cumplir su cometido esencial, esto es, velar por el mantenimiento de la paz y la seguridad internacionales, este Consejo puede adoptar las siguientes medidas: medidas que no implican el uso de la fuerza (las usualmente llamadas sanciones, contempladas en los artículos 40 y 41 de la Carta); medidas que implican uso de la fuerza (establecidas en los artículos 42 y siguientes de la Carta); otras medidas (que no se desprenden de manera tan explícita de la Carta pero que han constituido buena parte de la práctica del CSNU en los últimos años a través de un rol parecido al de un legislador, por ejemplo, con la adopción de acciones contra el terrorismo y la creación de tribunales penales ad hoc).

Nos interesan ahora aquéllas que no implican uso de la fuerza y que se han dado en llamar sanciones internacionales.

Para llevar a cabo una acotación conceptual del término sanción internacional consideramos oportuno recurrir en primer lugar a una definición de la noción de sanción.

En este sentido, el Diccionario de la lengua española ofrece diversas acepciones $^{8}$ de entre las cuales dos, la idea de "pena que una ley o un reglamento establece para sus infractores" o la de "mal dimanado de una culpa o yerro y que es como su castigo o pena", pueden emplearse para perfilar el concepto de sanción internacional, dejándose de lado el senti-

7 Véase el siguiente vínculo de la ONU en el que se recoge toda la información concerniente a las propuestas de reforma de la organización emanadas de diferentes órganos, gobiernos, personalidades y grupos de alto nivel: http://www.un.org/spanish/refor$\mathrm{mal}$.

8 Sanción. (Del lat. sanct?o, -ônis). 1. f. Pena que una ley o un reglamento establece para sus infractores. 2. f. Autorización o aprobación que se da a cualquier acto, uso o costumbre. 3. f. Acto solemne por el que el jefe del Estado confirma una ley o estatuto. 4. f. Mal dimanado de una culpa o yerro y que es como su castigo o pena. 5. f. Estatuto o ley. Real Academia Española, Diccionario de la lengua española, 22a. ed., Madrid, t. II, 2001. 
do de ratificación, aprobación o autorización de un acto determinado que también se atribuye al término considerado. En esa línea encontramos igualmente algunas definiciones doctrinales sobre el término sanción, partiendo por cierto desde una visión positivista. Así "[L]a sanción es... aquella fuerza física (latente o efectiva) ejercida por la comunidad jurídica para reprimir los actos desviantes de los miembros de tal comunidad y para consolidar los valores que están en la base social de la comunidad jurídica en cuestión". ${ }^{9}$

Ciñéndonos estrictamente al plano del derecho internacional podemos recordar que ya hubo intentos por perfilar un concepto de sanción internacional en el marco de los trabajos preparatorios sobre el tema de la responsabilidad de los Estados por hechos internacionalmente ilícitos, básicamente por los aportes del relator Roberto Ago y la distinción respecto de la figura de la "reparación". Según se suele indicar, a partir de estos trabajos, serían tres los elementos de una sanción internacional, a saber: debe ser una respuesta a un acto ilícito previo, debe ser un acto coercitivo y debe ir dirigido a reprimir las conductas desviantes. ${ }^{10}$

Ahora bien, dado que el régimen de las sanciones internacionales que estudiamos encuentra para el CSNU su justificación normativa en los artículos 39 a 41 de la Carta de Naciones Unidas, si tuviéramos que darle un contenido a partir de tales ideas conceptuales parece más apropiado optar por la primera de las acepciones referidas, esto es, la de pena derivada de una ley o reglamento impuesta a sus infractores, noción que se aviene mucho con las ideas sentadas por Ago.

No obstante ello, es conveniente hacer algunas precisiones en esta parte. Los artículos señalados no hacen alusión en ningún momento al término sanción. La expresión empleada por la Carta de Naciones Unidas es la de "medidas".

Sin embargo, la práctica y la doctrina internacionalistas recurren con carácter general al término sanción, lo que en ocasiones resulta objeto de debate precisamente por el carácter de punición que encierra esta palabra y las reales facultades que la Carta otorga al Consejo de Seguridad.

9 Ripol Carulla, S., El desarrollo de la potestad sancionadora del Consejo de Seguridad de las Naciones Unidas (contribución al estudio del concepto de sanción internacional), Bilbao, Instituto Vasco de Administración Pública, 2003, p. 23.

10 Ibidem, pp. 33-58. 
En efecto, la definición de sanción recogida en el Diccionario de la lengua española se refiere a pena o castigo, mientras que el espíritu de los artículos 40 y 41 de la CNU no es tanto el de punir o castigar como el de "mantener o restaurar la paz y la seguridad internacionales" (artículo 39, Carta de Naciones Unidas) que se han visto amenazados como consecuencia del incumplimiento de una obligación internacional grave por uno o más Estados.

La cuestión ha sido abordada incluso desde la Secretaría General de Naciones Unidas dada la imprecisión con que el CSNU actúa en algunas ocasiones. ${ }^{11}$

Asimismo, los aportes doctrinales que hemos expuesto también descansan sobre una idea diversa al espíritu del capítulo VII de la carta onusiana.

No obstante este importante debate sobre la denominación de estas medidas en razón de las facultades efectivas que tiene el CSNU, lo cierto es que existe consenso en la doctrina sobre la idea de que constituyen una forma de asegurar la aplicación de las normas internacionales, así como en buena medida también se considera que lo son las "contramedidas" de que habla el Proyecto de Artículos sobre Responsabilidad de los Estados, de 2001, pero que responden a la acción colectiva manifestada por organismos internacionales, mientras las "contramedidas" son la respuesta unilateral a las violaciones al derecho internacional. ${ }^{12}$

11 En ese sentido, véase el informe Suplemento al Programa de Paz de 1995, en donde el secretario general, Boutros Boutros-Gali, explica que "el objetivo de las sanciones es modificar la conducta de una parte que pone en peligro la paz y la seguridad internacionales, y no castigar ni tomar represalias de otra forma... El hecho de que en los últimos tiempos el Consejo de Seguridad haya recurrido en mucha mayor medida que antes a ese instrumento, ha puesto de manifiesto varias dificultades, especialmente en lo que atañe a los objetivos de las sanciones, la vigilancia de su aplicación y de las consecuencias que traen consigo, y los efectos no intencionales que producen... No siempre se han definido con claridad los objetivos de la imposición de regímenes específicos de sanciones. De hecho, se diría que esos objetivos cambian a lo largo del tiempo. Debido a esta mutabilidad y falta de precisión, al Consejo de Seguridad le resulta difícil llegar a un acuerdo sobre cuándo se puede considerar que se han logrado los objetivos $\mathrm{y}$, por lo tanto, se pueden levantar las sanciones". Casanovas, O., Casos y textos de derecho internacional público, 5a. ed., Madrid, Tecnos, 2005, p. 872.

12 González Campos, J. D. et al., Curso de derecho internacional público, 2a. ed. rev., Madrid, Civitas, 2002, p. 406. No obstante, el relator especial G. Gaja también ha previsto las contramedidas como respuesta de las organizaciones internacionales a violaciones de derecho internacional, en su propuesta al artículo 19 del nuevo proyecto sobre 
Sobre estas bases daremos un concepto de ellas que se puede extraer de la doctrina y que nos ha parecido pertinente en cuanto refleja lo que están siendo hoy estas sanciones adoptadas por el CSNU más allá de las discusiones doctrinales. "En el derecho internacional actual sólo pueden ser consideradas como verdaderas 'sanciones internacionales' las medidas de carácter colectivo que se adoptan en el seno de las organizaciones internacionales frente al incumplimiento de una obligación internacional grave por uno o más Estados". ${ }^{13}$

\section{La evolución en el Consejo de Seguridad desde las sanciones globales a las sanciones inteligentes}

Las sanciones impuestas por el CSNU son una forma de reacción colectiva frente a las amenazas a la paz mundial que se aplican en el marco de una organización internacional, la ONU, y por tanto se revelan como el mecanismo adecuado para responder frente a graves violaciones del derecho internacional. ${ }^{14}$ Aunque también puede llamarse genéricamente "sanciones" a aquellas medidas que implican uso de la fuerza, lo cierto es que la propia práctica de la Organización indica que las "sanciones internacionales" son estrictamente aquéllas a que se refiere el artículo 41 de la Carta. ${ }^{15}$ Conviene hacer dos precisiones sobre las medidas aludidas

la responsabilidad de las organizaciones internacionales. La Comisión de Derecho Internacional ha decidido analizar esta cuestión posteriormente, cuando estudie hacer efectiva la responsabilidad de una organización internacional.

13 González Campos, J. D. et al., op. cit., nota anterior, pp. 406 y 407.

14 Esto es importante aclararlo pues, como señalan los profesores González Campos, Sánchez Rodríguez y Andrés Sáez de Santa María, en el marco de las organizaciones internacionales "cabe distinguir dos grupos de sanciones. El primero incluye las que se derivan del incumplimiento reiterado de sus obligaciones con la Organización por parte de un Estado miembro; lo que puede entrañar bien la pérdida del estatus, bien una limitación temporal de sus derechos... El segundo grupo... es el de las sanciones frente a una violación del derecho internacional con graves consecuencias para la comunidad internacional". Ibidem, p. 406.

15 Dice la citada disposición: "El Consejo de Seguridad podrá decidir qué medidas que no impliquen el uso de la fuerza armada han de emplearse para hacer efectivas sus decisiones, y podrá instar a los miembros de las Naciones Unidas a que apliquen dichas medidas, que podrán comprender la interrupción total o parcial de las relaciones económicas y de las comunicaciones ferroviarias, marítimas, aéreas, postales, telegráficas, radioeléctricas, y otros medios de comunicación, así como la ruptura de relaciones diplomáticas". 
en este precepto, a saber, que la enumeración en él contenida no se considera taxativa y que los ejemplos que se usan corresponden a la realidad de 1945, muy distinta a la vida y las circunstancias de nuestros días.

Los cambios vividos por la sociedad internacional y los efectos, a veces perniciosos, derivados de la aprobación y aplicación de sanciones por el CSNU propiciarán la evolución de dichas sanciones al tipo de medida que hoy se conoce como sanciones inteligentes y que, al decir casi unánime de la doctrina y de la propia Organización de las Naciones Unidas, han de ser las únicas que se apliquen en nuestro tiempo.

En efecto, el análisis histórico de las sanciones aplicadas por el CSNU muestra que se ha avanzado desde sanciones de carácter global, que no precisaban claramente sus destinatarios ni su duración ni su objeto, en definitiva, sus límites, hasta sanciones más específicas o, como las llama la propia ONU, sanciones selectivas. La historia de los últimos veinticinco años nos ofrece claros ejemplos.

Cuando a primeros de agosto de 1990 Irak invade Kuwait, el CSNU toma de inmediato nota de la trascendencia del tema y despliega su maquinaria aprobando varias resoluciones ${ }^{16}$ que recibirían críticas de la comunidad internacional, especialmente por la imprecisión de las sanciones decretadas, su dudosa juridicidad y los efectos que estas traerían años más tarde. ${ }^{17}$ Para los efectos de este estudio la decisión más importante del CSNU es la Resolución 661, de 6 de agosto de 1990, ${ }^{18}$ en la que se establecen sanciones económicas de carácter global en virtud de la inte-

16 Algunas de las cuales, por cierto, serían "revividas" por los Estados Unidos en 2003 para justificar su invasión de Irak.

17 "El impacto de las sanciones de Naciones Unidas sobre Irak ha desencadenado un debate mundial sobre todos los aspectos de las sanciones, incluida su legalidad". O'Connell, M., "Debating the Law of Sanctions", European Journal of International Law, vol. 13, núm.1, 2002, p. 63.

18 Respondiendo al encomiable propósito divulgativo e informativo perseguido por la ONU, ésta pone a disposición de todos los ciudadanos un nutrido archivo de documentos representativos de la labor de la Organización a lo largo de sus ya más de seis décadas de existencia. En concreto, las resoluciones adoptadas por el Consejo de Seguridad desde 1946 hasta el momento presente son accesibles desde el siguiente vínculo: http://www.un.org/spanish/documents/scres.htm. A través del mismo puede accederse al contenido de todas las resoluciones del CSNU que serán citadas a lo largo de nuestro trabajo. Existe asimismo una página Web, en español, del centro de documentación de la ONU: http://www.un.org/spanish/documents/index.html, que contiene enlaces para acceder a los documentos de los diferentes órganos onusianos. 
rrupción de las relaciones de terceros países con Irak, exceptuando las necesidades de carácter humanitario, situación que ocasionó más de algún problema y que no consiguió que se produjesen infracciones a lo establecido en ella. ${ }^{19}$ A partir de otras resoluciones posteriores adoptadas en el marco de la, ahora denominada, primera crisis de Irak, la idea de una sanción global se vio reforzada y, tras los más de diez años durante los cuales se mantuvieron vigentes, dejaron ver que, en contra de lo esperado, el principal afectado no fue precisamente el gobierno de Hussein sino la población civil iraquí. ${ }^{20}$

Con la experiencia de Irak como telón de fondo, la década de los noventa $^{21}$ ha sido el escenario temporal en el que se ha producido la evolución desde la sanción global, indiscriminada, que extiende sus inevitables efectos perniciosos al grueso de la población civil, hasta la concepción actual de sanción selectiva, denominada inteligente (como si

19 Por la resolución 661 se estableció un Comité para supervisar la relación entre Irak y Kuwait. La invasión de Irak por Estados Unidos en 2003, y la subsiguiente caída del régimen de Sadam Hussein hace ahora cuatro años, trajeron consigo, como todos sabemos y vemos diariamente en los medios de comunicación, una precaria situación de enorme belicosidad y continuos enfrentamientos en la región. El CSNU hubo de seguir ocupándose de este asunto y sustituyó, sin solución de continuidad, el citado Comité por uno nuevo creado el 24 de noviembre de 2003 en virtud de la resolución 1518; véase el siguiente vínculo: http://www.un.org/spanish/sc/committees/1518/index.shtml. El propósito principal del primer comité era identificar a los altos funcionarios del régimen de Irak y a sus familiares inmediatos, incluidas las entidades de propiedad de esas personas o de personas que actuaban en su nombre. El nuevo comité se encarga de actualizar las listas de personas y entidades identificadas; asimismo, el Consejo de Seguridad decidió que se considerara la posibilidad de autorizar al Comité a realizar la tarea adicional de observar el cumplimiento por los Estados miembros de sus obligaciones relacionadas con el embargo de armas impuesto a Irak.

20 "Se ha observado en numerosas ocasiones, por ejemplo, que en el caso de Irak la imposición de sanciones fue acompañada de un severo deterioro del bienestar socio-económico de la población general. La degradación de la infraestructura civil del país condujo, entre otras cosas, a una disminución de la producción de alimentos y de la calidad del agua, un incremento de enfermedades prevenibles a través de vacunas, malaria, fiebre tifoidea y tuberculosis, y un creciente índice de malnutrición crónica y mortalidad infantil". Craven, M., op. cit., nota 3, p. 45.

21 De hecho, esta década ha sido considerada como "La década de las sanciones" en un estudio respaldado por la International Peace Academy (http://www.ipacademy.org/) y que adoptó la forma de libro en 2000: Cortright, David y López, G. A., The Sanctions Decade: Assessing UN Strategies in the 1990s, Londres, Lynne Rienner Publishers, 2000. 
de un ser vivo se tratase), que pretende limitar su espectro de actuación a los agentes responsables de la amenaza a la paz y seguridad internacionales, el objeto preciado de salvaguarda por el CSNU. El reto que se le presenta a este órgano, a la Organización de las Naciones Unidas en sí misma considerada y a la comunidad internacional en su conjunto es hacer de esta mera concepción, la de sanción inteligente, una realidad efectiva, casi tangible. Los hechos, testigos implacables de la verdad, demuestran que aún queda mucho por hacer. En efecto, no es suficiente, citando a $\mathrm{K}$. Annan, hacer que estas sanciones sean "cada vez más listas", el desafío es alcanzar el consenso en relación a los fines específicos que han de satisfacer estas sanciones. ${ }^{22}$

Una de las contribuciones más destacadas al perfeccionamiento del sistema de imposición de sanciones ha venido de la mano de la creación, en cada caso concreto de establecimiento de las mismas, de un llamado "Comité de Sanciones". ${ }^{23}$ Estos comités son órganos subsidiarios del Consejo de Seguridad y están integrados por representantes de todos los miembros de las Naciones Unidas. En la propia página Web de estos comités se plasma el fin último del Consejo de Seguridad en la materia que nos ocupa y que no es sino alcanzar un "criterio más refinado en el diseño y aplicación de las sanciones obligatorias", lo que implica disponer "medidas dirigidas contra agentes concretos, así como excepciones de carácter humanitario incluidas en las resoluciones del Consejo de Seguridad". Se expresa en términos muy precisos el Consejo cuando dice que "las sanciones selectivas pueden incluir, por ejemplo, la congelación de activos o el bloqueo de transacciones financieras de las elites políticas o

22 Precisamente en el seminario en que se dio a conocer el estudio que sirve de base a la obra citada en la nota anterior, el ya ex secretario general Kofi Annan pronunció en abril de 2000 unas palabras en las que recordaba el camino que ha de recorrerse hasta conseguir que estas sanciones tengan un resultado eficaz y poco o nada lesivo para la población civil: Pero permítanme sugerir que no es suficiente sólo con hacer las sanciones "más inteligentes". El reto es alcanzar un consenso acerca de los precisos y específicos objetivos de las sanciones, ajustar los instrumentos en consecuencia y entonces proveer los medios necesarios. Ello requiere, por parte del Consejo de Seguridad y de sus Estados miembros, una voluntad de abordar no sólo cuestiones técnicas operativas, sino también las más amplias cuestiones políticas sobre cómo aseguramos mejor el más completo y amplio cumplimiento de la voluntad de la comunidad internacional por parte de los Estados recalcitrantes. http://www.un.org/sc/committees/sanctions/sgstatement.htm.

23 El vínculo de enlace con la página general de introducción a estos comités es el siguiente: http://www.un.org/spanish/sc/committees/index.shtml. 
entidades cuya conducta fue la causante original de las sanciones". ${ }^{24} \mathrm{En}$ su aspiración por llevar a cabo este "refinamiento", el CSNU ha encontrado no pocos obstáculos por superar, para los cuales ha recurrido a nuevos y diversos instrumentos como pueden ser la creación de grupos de expertos, mecanismos de vigilancia y grupos de supervisión o la petición de informes al SGNU. Destaca en este sentido la puesta en marcha del Grupo de Trabajo sobre Cuestiones Generales de las Sanciones ${ }^{25}$ encargado de generar y recopilar documentación e informes de cierta relevancia en el ámbito de las sanciones. ${ }^{26}$

Pese a los intentos de mejora, la labor del CSNU no ha estado exenta de críticas, pero es precisamente este "propósito de enmienda" del Consejo uno de los puntos fuertes de los cambios que se vienen promoviendo en el contexto de la reforma global del sistema de Naciones Unidas. ${ }^{27}$ Frente al panorama de patente pesimismo que encontramos hoy en Irak, ${ }^{28}$ región que albergó a la mítica Mesopotamia y donde surgió la civilización sumeria, considerada la civilización más antigua del mundo, el hecho de llevar la vista a la que fuera la antigua Yugoslavia nos devuelve algo de esperanza. Como consecuencia de los acontecimientos que allí se sucedieron desde finales de los ochenta y durante buena parte de la década siguiente, el CSNU se vio compelido a adoptar un papel relevante en la escena internacional en los términos del mandato que le dirige la CNU.

La articulación de la imposición de sanciones en el caso de la ex Yugoslavia supuso algunos de los avances que en esta materia se han producido y abrió paso al desarrollo posterior al que estamos asistiendo. Así, la

24 Extraído textualmente del instrumento electrónico citado supra.

25 http://www.un.org/spanish/docs/comitesanciones/index.html.

26 Hasta enero de 2007, estaban en funcionamiento 14 comités del Consejo de Seguridad y seis grupos de trabajo. Al documento que recoge la composición de todos ellos, se puede acceder desde la página principal de los comités de sanciones recogido supra.

27 Cuestión que trataremos más ampliamente en el apartado siguiente, haciendo alusión a aquellos documentos concretos en que la reforma del sistema de sanciones es mencionado.

28 Es extraño el día en que los noticiarios no recogen un ataque mortal en una o varias ciudades iraquíes. Así, un domingo cualquiera, como el pasado 18 de marzo de 2007, varios actos de violencia en la capital, Bagdad, dejaron un balance de cinco muertos (véase ad ex. http://edition.cnn.com/2007/WORLD/meast/03/18/iraq.main/index.html.), cifra a primera vista poco relevante, pero que sumada día tras día, y teniendo en cuenta que se trata siempre de pérdidas de vidas humanas, hacen estremecer a cualquiera. 
Resolución 713 del CSNU, de 25 de septiembre de 1991, sin dejar de invocar en ningún momento el capítulo VII de la CNU, decidió en su punto 6 que, "para establecer la paz y la estabilidad en Yugoslavia, todos los Estados pondrán en vigor de inmediato un embargo general y completo a todas las entregas de armamento y pertrechos militares". Como se deduce del grueso de resoluciones del Consejo, el embargo de armas y demás material bélico es probablemente la medida más típica de cuantas se establecen.

En una Resolución posterior, la 724, de 15 de diciembre del mismo año, se establecieron nuevos mecanismos que deberían contribuir a garantizar la estabilidad en una zona que desgraciadamente sería después escenario de atroces acontecimientos. Uno de estos mecanismos fue la creación de un Comité del Consejo de Seguridad, integrado en este caso por todos los miembros del Consejo ${ }^{29} \mathrm{y}$ encargado fundamentalmente de examinar los informes que todos los Estados estaban obligados a presentar en relación con las medidas que hubieran adoptado para cumplir el embargo decretado por la Resolución $713 .{ }^{30}$ A grandes rasgos, este Comité debía desempeñar una labor general de vigilancia del cumplimiento de la medida mencionada, recabando y produciendo la informa-

29 Los comités de sanciones creados desde 1999 no estarían integrados, como éste de Yugoslavia, por todos los miembros del Consejo. A partir de entonces, cada año, el presidente del CSNU emite una nota en la que se recoge la composición de los Comités y Grupos de Trabajo en conformidad con lo dispuesto en el apartado b) del párrafo 4 de la nota del presidente del Consejo de Seguridad de fecha 30 de octubre de 1998 (S/1998/1016), http://daccessdds.un.org/doc/UNDOC/GEN/N98/331/10/PDF/N9833110. pdf? OpenElement, y tras la celebración de consultas entre los miembros del Consejo. En la mencionada nota de 1998 se establece que: "b) Con efecto a partir de 1999, cada comité de sanciones designará a su mesa, previa celebración de consultas entre los miembros del Consejo, en su primera reunión si ésta tuviera lugar en el mes de enero, o por escrito, a solicitud de la Presidencia del Consejo, con arreglo al procedimiento de no objeción". Para 2007, véase supra nota 23.

30 A primera vista parece que un embargo general de armas como el que establecía la Resolución 713 no debía afectar en gran medida a la población civil. No obstante, la Resolución 724 velaba en cierta medida por la protección de los derechos de dicha población al alentar al secretario general a "continuar sus actividades humanitarias en Yugoslavia, junto con el Comité Internacional de la Cruz Roja, el Alto Comisionado de las UN para los refugiados, el Fondo de UN para la infancia y otras organizaciones humanitarias apropiadas" y "a adoptar con urgencia medidas prácticas para atender a las críticas necesidades del pueblo". 
ción pertinente, así como manteniendo informado de los progresos y retrocesos al SGNU.

Con todas estas medidas el sistema de sanciones empezaba a despegar el vuelo hacia el deseado refinamiento que todavía hoy, más de 15 años después, no ha terminado. Como veremos enseguida, las resoluciones posteriores introducen medidas mucho más detalladas y que normalmente van a acompañadas por excepciones que no pretenden sino salvaguardar los derechos más básicos de la población civil.

La situación de los Balcanes impactó fuertemente al resto del continente europeo y tuvo graves consecuencias humanitarias. Hoy puede decirse que la zona avanza a buena marcha hacia una recuperación completa de sus instituciones y del orden político y social, aunque, claro está, siempre queden cosas por hacer. Muestra de esta recuperación es el contenido de la Resolución 1074, de 1o. de octubre de 1996, sobre arreglo político de los conflictos en la ex Yugoslavia. En esta breve pero esencial Resolución, el CSNU, además de disolver el Comité establecido en la Resolución 724, "acoge complacido" el reconocimiento recíproco y destaca la importancia de la plena normalización de las relaciones en la región. Aprobada después de la celebración de elecciones en Bosnia Herzegovina en septiembre de 1996, en ella el CSNU cumple lo prometido en la Resolución 1022, ${ }^{31}$ de 22 de noviembre de 1995, y deja por ende sin efecto las medidas a las que se hace referencia en el párrafo $1^{32}$ de esa Resolución. Todas estas resoluciones, que son ofrecidas aquí como paradigma de la situación previa al momento presente de evolución del sistema de imposición de sanciones, muestran lo complejo de los mecanismos

31 “4. Decide además que dejará sin efecto las medidas descritas en el párrafo 1 supra el décimo día a contar de la celebración de las primeras elecciones libres y limpias previstas en el Anexo 3 del Acuerdo de Paz, a condición de que las fuerzas de los serbios de Bosnia se hayan retirado de las zonas de separación y hayan continuado respetándolas conforme a lo dispuesto en el Acuerdo de Paz".

32 "Actuando en virtud del capítulo VII de la Carta de las Naciones Unidas, 1. Decide que las medidas impuestas o reafirmadas por las resoluciones 757 (1992), 787 (1992), 820 (1993), 942 (1994), 943 (1994), 988 (1995), 992 (1995), 1003 (1995) y 1015 (1995) quedan suspendidas por tiempo indefinido con efecto inmediato... a condición de que, si el secretario general informa al Consejo de que la República Federativa de Yugoslavia no ha suscrito oficialmente el Acuerdo de Paz en la fecha anunciada por el Grupo de Contacto a ese fin y de que las demás partes en el Acuerdo de Paz han expresado su disposición a suscribirlo, las medidas descritas supra serán automáticamente restablecidas desde el quinto día a contar de la fecha de dicho informe". 
entonces empleados. Así, la Resolución 1022 citada supra hace mención a nada más y nada menos que nueve resoluciones distintas en las que las sanciones y medidas para el restablecimiento de la paz y la seguridad en la zona habían sido establecidas. El sistema es, en definitiva, muy complejo y de difícil comprensión en toda su magnitud a menos que todas y cada una de las resoluciones sean detenidamente estudiadas.

Hoy en día, cuando hablamos de sanciones inteligentes estamos refiriéndonos principalmente a los enormes progresos que el Consejo de Seguridad ha realizado en su aspiración por diseñar unos mecanismos más sistemáticos y menos complejos. Algo diferente es que el nuevo sistema respete en toda su extensión los derechos fundamentales de la población civil localizada en una zona conflictiva que esté siendo atendida por el Consejo de Seguridad. Al menos en el ámbito formal el CSNU ha pasado de plasmar sus decisiones de manera dispersa y deshilvanada en multitud de resoluciones a alcanzar una sistemática que facilita el conocimiento de las medidas decididas por el CSNU y que deben ser adoptadas por los países y dadas a conocer al resto de la comunidad internacional. ${ }^{33}$

Para centrarnos más en aquello que define a las sanciones inteligentes o selectivas, recogiendo los términos empleados desde las diferentes tribunas de las Naciones Unidas, hemos de decir que se trata de la plasmación en las resoluciones que las recogen de los tres elementos que contribuyen a precisar los límites de la sanción establecida. Así, la decisión debe precisar el objeto de la sanción, el sujeto de la misma y, algo que resulta determinante para la salvaguarda de las necesidades y derechos básicos de la población civil, su duración. Este último elemento no implica necesariamente que las resoluciones deban referirse a un lapso temporal acotado durante el cual la sanción estará vigente. Antes bien, la

33 En este sentido, basta con comparar lo sistemático del contenido y de la presentación en soporte Web de los documentos recientemente aprobados por el Consejo de Seguridad, con la avalancha de documentos generados por conflictos anteriores, como el expuesto de la antigua Yugoslavia. En la misma línea, el CSNU está haciendo esfuerzos por condensar y sistematizar las decisiones adoptadas en relación con el régimen talibán y los integrantes del grupo terrorista Al Qaeda, cuyas actuaciones inquietan y amenazan a gran parte de la comunidad internacional, y no han sido en ningún momento desatendidas por el órgano ejecutivo de las Naciones Unidas. Véase a este respecto el siguiente vínculo: http://www.un.org/spanish/sc/committees/1267/index.shtml del Comité del Consejo de Seguridad establecido en virtud de la resolución 1267, de 15 de octubre de 1999, relativa a Al-Qaida, y los talibanes, personas y entidades asociadas, conocido también como Comité de Sanciones contra Al-Qaida y los talibanes. 
práctica viene siendo determinar qué circunstancias favorables al mantenimiento de la paz y la seguridad internacionales, se entiende, deben concurrir para que las medidas dispuestas dejen de aplicarse, en su totalidad o bien sólo en parte.

Ejemplos de esta "triple precisión" pueden encontrarse en muchas resoluciones aprobadas por el CSNU desde finales de la década de los noventa, habiéndose seguido esta práctica incondicionalmente desde 2000. Puede citarse a título ilustrativo la Resolución 1160, de 31 de marzo de 1998, aprobada en el contexto de la crisis de los Balcanes. Esta Resolución se ocupa concretamente de la situación de Kosovo. ${ }^{34}$ En el punto 8 de la Resolución 1160, el CSNU:

8. Decide que todos los Estados, para promover la paz y la estabilidad en Kosovo, deberán prohibir la venta o el suministro a la República Federativa de Yugoslavia, incluida Kosovo, por sus nacionales o desde sus territorios o utilizando buques o aviones de su pabellón, de armamentos y material conexo de cualquier tipo, incluidas armas y municiones, vehículos y equipo militares y las piezas de repuesto correspondientes, e impedirán la provisión de armas y el adiestramiento de elementos para llevar a cabo actividades terroristas en ese territorio.

Y así fijar claramente el objeto de la sanción, esto es, la prohibición de venta o suministros de material bélico en sentido amplio.

Las resoluciones aprobadas a partir de 2000 han sido mucho más específicas a la hora de acotar los límites de las sanciones ${ }^{35}$ puesto que en ellas se precisa el objeto, como ya se venía haciendo anteriormente y hemos visto plasmado en la Resolución 1160, y además se suele distinguir entre aquellos sujetos cuyas actividades amenazan potencial o realmente a la paz y a la seguridad internacionales o de la región de que se trate y el resto de la población civil. La salvaguarda de las necesidades y los dere-

34 Provincia serbia cuya administración es conducida por la ONU sin la participación del gobierno serbio (en virtud de la Resolución del Consejo de Seguridad 1244, de 10 de junio de 1999) por la Misión de Naciones Unidas en Kosovo (UNMIK), que usa la bandera de la ONU, siendo garantizada la seguridad en la región por la KFOR, la Fuerza de la OTAN en Kosovo.

35 Destaca el dato, simplemente formal, pero revelador del pretendido perfeccionamiento de las resoluciones del CS, de la mayor extensión de las mismas, superando la mayor parte de ellas las siete páginas, siendo así que en los noventa difícilmente ocupaban más de cuatro. 
chos básicos de la misma preocupa sobremanera a la ONU, especialmente tras los fiascos vividos en este ámbito durante conflictos pasados, y para mantenerla se recurre a la inserción de cláusulas en las resoluciones del Consejo que recogen excepciones a las sanciones impuestas, justificadas estas últimas siempre por razones humanitarias. En este sentido podemos citar a título de ejemplo la Resolución 1343, de 7 de marzo de 2001, relativa a la situación en Liberia, en la que el CSNU, atendiendo al llamamiento hecho por la Asamblea General el 1o. de diciembre de 2000 , adopta medidas respecto de las cuales debían comprometerse "todas las partes interesadas, inclusive los países productores, elaboradores, exportadores e importadores de diamantes, así como la industria del diamante, con el fin de romper el vínculo entre los diamantes y los conflictos armados" e igualmente realizar un llamamiento a "todos los Estados para que apliquen íntegramente las medidas decididas por el Consejo de Seguridad con el objeto de romper el vínculo entre el comercio de diamantes de las zonas en conflicto y el suministro a los movimientos rebeldes de armas, combustibles u otro material prohibido". ${ }^{36}$ El objeto preciso de las sanciones adoptadas en esta resolución era el de exigir que el gobierno de Liberia pusiera fin de inmediato al apoyo al Frente Revolucionario Unido (FRU) de Sierra Leona, toda vez que el propio Consejo determinó que dicho apoyo activo constituía una amenaza a la paz y la seguridad internacionales en la región. Más que las medidas impuestas, que serán las que se repitan desde entonces en todas las resoluciones que recogen sanciones, ${ }^{37}$ podemos destacar otros datos. Por un lado, la excepción a algunas de estas limitaciones cuando se trate de "suministros de equipo militar no mortífero destinado únicamente a atender necesidades humanitarias o de protección" 38 o "ropa de protección, incluidos los chalecos antimetralla y los cascos militares, que exporten temporalmente a Liberia el personal de las Naciones Unidas, los representantes de medios de información y el personal humanitario, de desarrollo y conexo,

36 Véase la Resolución 1343.

37 En este caso, y entre otras, la expulsión de Liberia de miembros del FRU, la prohibición de importaciones de diamantes de Sierra Leona, limitaciones al apoyo financiero y militar, congelación de activos, etcétera.

38 Punto 5 c) de la Resolución 1343. 
exclusivamente para su propio uso". ${ }^{39}$ Por otro lado, se consigue la precisión del sujeto destinatario de la sanción cuando dispone que:

Todos los Estados adopten las medidas necesarias para impedir la entrada en sus territorios, o el tránsito por ellos, de altos funcionarios del Gobierno de Liberia y sus cónyuges, así como de personal militar y sus cónyuges, y de cualesquiera otras personas que presten apoyo financiero y militar a grupos rebeldes armados en los países vecinos de Liberia, en particular el FRU de Sierra Leona. ${ }^{40}$

También se introducen algunas excepciones en cuanto a la precisión hecha de los sujetos en los siguientes términos literalmente extraídos del texto de la resolución: [el Consejo de Seguridad]:

b) Decide que las medidas impuestas en virtud del apartado a) supra no se apliquen en los casos en que el Comité establecido en virtud del párrafo 14 infra determine que un viaje se justifique por razones humanitarias, incluidas las obligaciones religiosas, o en los casos en que el Comité llegue a la conclusión de que la exención promovería el cumplimiento por Liberia de las exigencias del Consejo o contribuiría a la solución pacífica del conflicto en la subregión. ${ }^{41}$

Destacamos finalmente la última de las precisiones recogidas en la Resolución 1343, que estamos estudiando, y que se introduce actualmente en la mayoría de las resoluciones del CS en las que se imponen sanciones. Se trata del establecimiento de un límite a la duración de dichas sanciones. Así, después de fijar el momento preciso en el que las medidas debían entrar en vigor, lleva a cabo la acotación temporal de aplicación de las mismas y distingue para ello entre, en primer lugar, las relativas a la prohibición de venta o suministro de todo tipo de material bélico y, en segundo lugar, las que se refieren a la prohibición de la importación directa o indirecta desde Liberia de cualesquiera diamantes en bruto y a la limitación al tránsito de las personas antes señaladas. El primer grupo de medidas debía permanecer en vigor durante 14 meses y, al cabo de ese plazo, el Consejo debía decidir si el Gobierno de Liberia había cumplido

39 Punto 5 d) de la Resolución 1343.

40 La cursiva es nuestra. Punto 7 a) de la Resolución 1343.

41 Punto 7 b) de la Resolución 1343. 
o no lo exigido por el CSNU y, en consecuencia, si mantendría o no en vigor esas medidas por un nuevo periodo en las mismas condiciones. ${ }^{42}$ En los mismos términos, pero fijando en este caso un plazo de 12 meses, se refiere el Consejo al segundo grupo de medidas señaladas. ${ }^{43}$ Destaca la siguiente disposición de la Resolución 1343, en la que se prevé que las sanciones establecidas por la misma:

Queden sin efecto inmediatamente si el Consejo, teniendo en cuenta, entre otras cosas, los informes del Grupo de Expertos y los informes del secretario general, las aportaciones de la CEDEAO, toda información pertinente que proporcionen el Comité establecido en virtud del párrafo y el Comité establecido en virtud de la resolución 1132 (1997) y toda otra información pertinente, determina que el Gobierno de Liberia ha cumplido las exigencias establecidas en el párrafo. ${ }^{44}$

Se establece pues, junto a la acotación temporal de vigencia de las sanciones durante 14 y 12 meses respectivamente, sujetos a prórroga a decisión del Consejo, la posibilidad de dejar sin efecto tales sanciones si el Consejo lo considera oportuno, con lo que se favorece la capacidad decisoria y de apreciación del propio Consejo, lo que puede contribuir en última instancia a limitar los efectos perniciosos que se derivan inexorablemente de la aplicación de estas medidas, en ocasiones de variado alcance, pudiendo llegar a limitar gravemente el desarrollo y abastecimiento de amplios sectores sociales y a repercutir negativamente, en consecuencia, sobre el fortalecimiento de los derechos humanos en cuanto bien protegido por la ONU.

Una vez realizado el análisis de una Resolución tomada como modelo para poner de manifiesto la triple especificidad que el CSNU está introduciendo en sus resoluciones cuando éste se ve obligado a imponer sanciones, siempre en el contexto del capítulo VII de la CNU, haremos alusión a dos de las dos resoluciones más recientes del Consejo que además se refieren a las dos situaciones de mayor repercusión actualmente en el ámbito mediático de alcance internacional. Evidentemente, se trata de los acontecimientos que se suceden en Irán y Corea del Norte desde hace algún tiempo, todos ellos relacionados con la potencial amenaza

42 Punto 9 de la Resolución 1343.

43 Punto 10 de la Resolución 1343.

44 Punto 11 de la Resolución 1343. 
que para la paz y la seguridad internacionales suponen los programas de desarrollo nuclear que se llevan a cabo en ambos países y los ensayos con armas nucleares que desde Pyongyang se dice haber ejecutado en los dominios territoriales norcoreanos.

En el último trimestre de 2006, el Consejo de Seguridad hubo de aprobar sendas resoluciones que entroncaban directamente con la protección del sistema de no proliferación nuclear garantizado por el TNP y por las actividades de la Agencia Internacional de la Energía Atómica. ${ }^{45}$ La cuestión de la proliferación de armas nucleares, químicas y biológicas fue la tónica durante la Guerra Fría, cuestión que no ha dejado de preocupar de una manera especial a la ONU y a la comunidad internacional en ella representada ni siquiera tras el fin del orden llamado bipolar. Quizás por ser éste, el de las armas de destrucción masiva, un asunto determinante para la supervivencia de la raza humana y crucial en relación a la tarea atribuida al CSNU de mantener la paz y la seguridad internacionales, este órgano de la ONU actuó de manera inmediata tras conocer el anuncio hecho el 9 de octubre de 2006 por la República Popular Democrática de Corea de que había realizado un ensayo con un arma nuclear. Cinco días después, el 14 del mismo mes, era aprobada la Resolución 1718 en la que el CSNU, depurando su técnica cada vez más, reaccionó rápidamente ante lo que fue considerado como una provocación por buena parte de la comunidad internacional y articuló una serie de medidas con arreglo al artículo 41 del capítulo VII mediante las cuales se pretende limitar en la mayor medida posible la capacidad de Pyongyang para la producción de armas nucleares. Dos meses después, el 23 de diciembre de 2006, el CSNU aprobaba la Resolución 1737, esta vez relativa a Irán y a su programa nuclear.

Tanto la Resolución 1718 como la 1737 son muy parecidas en cuanto a su estructura y propósitos, lo cual no es de extrañar por cuanto comparten el mismo problema de fondo. Puede decirse, utilizando la expresión utilizada más arriba, que se trata de resoluciones "refinadas", más perfectas, que introducen la triple especificidad del objeto, los sujetos y

45 Véase el vínculo de este organismo internacional http://www.iaea.org/. La AIEA pone a disposición del público las últimas informaciones relativas a la situación que se vive, en el contexto de los programas de desarrollo nuclear, tanto en Irán (http:// www.iaea.org/NewsCenter/Focus/IaeaIran/index.shtml), como en la República Popular Democrática de Corea (http://www.iaea.org/NewsCenter/Focus/IaeaDprk/index.shtml). 
la duración de las medidas establecidas, si bien en relación a este último aspecto, el de la acotación temporal, no se fija un plazo preciso en meses. Estas resoluciones, en cambio, dejan abierta la posibilidad de que el CSNU pueda decidir que las sanciones dejen de aplicarse ${ }^{46}$ inmediatamente después de que los regímenes de Teherán y Pyongyang modifiquen su actitud. Quizás el no establecer un plazo determinado es muestra no sólo del ánimo de perjudicar lo menos posible y durante el menor tiempo posible a la población civil, sino que también revela el anhelo del CSNU de que se produzca tal cambio en la actitud de estos países, es decir, que se muestren proclives a la colaboración y a abandonar sus programas nucleares. ${ }^{47} \mathrm{Si}$ bien parece que es esto precisamente lo que está

46 La Resolución 1718 utiliza los siguientes términos: "[el Consejo de Seguridad]... 15. Afirma que mantendrá en examen permanente las actividades de la República Popular Democrática de Corea y que estará dispuesto a examinar la idoneidad de las medidas que figuran supra párrafo 8 , incluidos el reforzamiento, la modificación, la suspensión o el levantamiento de las medidas, según resulte necesario en ese momento en función del cumplimiento por la República Popular Democrática de Corea de las disposiciones de la presente resolución". En el caso de la Resolución 1737, la decisión del CSNU para suspender las medidas queda condicionada al estudio de los informes que el director general de la OIEA debía presentar a la propia OIEA y al Consejo de Seguridad: "[el Consejo de Seguridad]... 23. Pide que, en un plazo de 60 días, el director general del OIEA presente a la Junta de Gobernadores del OIEA, y en forma simultánea al Consejo de Seguridad para su examen, un informe en el que se indique si Irán ha llevado a cabo la suspensión completa y sostenida de todas las actividades mencionadas en esta resolución, y si está cumpliendo todas las medidas exigidas por la Junta de Gobernadores del OIEA, y las demás disposiciones de esta resolución; 24. Afirma que examinará las acciones del Irán a la luz del informe mencionado supra párrafo 23, que se presentará en un plazo de 60 días, y que: a) Suspenderá la aplicación de las medidas, siempre que Irán suspenda todas las actividades relacionadas con el enriquecimiento y el reprocesamiento, incluidas las actividades de investigación y desarrollo, y mientras dure la suspensión de Irán, que verificará el OIEA, para permitir las negociaciones; b) Dejará de aplicar las medidas especificadas en los párrafos $3,4,5,6,7,10$ y 12 de la presente resolución, tan pronto como determine que Irán ha cumplido cabalmente sus obligaciones en virtud de las resoluciones pertinentes del Consejo de Seguridad y los requisitos de la Junta de Gobernadores del OIEA, determinación que confirmará la Junta del OIEA; c) En caso de que el informe mencionado en el párrafo 23 supra indique que Irán no ha cumplido lo dispuesto en la presente resolución, adoptará, con arreglo al artículo 41 del capítulo VII de la Carta de las Naciones Unidas, otras medidas apropiadas para persuadir a Irán de que cumpla lo dispuesto en la presente resolución y los requisitos del OIEA, y subraya que deberán adoptarse otras decisiones si es necesario tomar tales medidas adicionales".

47 En el momento presente, Corea del Norte ha iniciado el desmantelamiento de su arsenal nuclear. Esta decisión se tomó tras la ronda de "conversaciones a seis" (que reú- 
ocurriendo en Corea del Norte, la realidad de Irán se revela absolutamente distinta. Basta recordar, a modo ilustrativo, la adopción por unanimidad de nuevas sanciones para Irán en la Resolución 1747, de 24 de marzo de 2007, del Consejo de Seguridad. ${ }^{48}$ Formalmente esta nueva Resolución responde al tipo de sanción selectiva o inteligente que hemos tratado de describir. ${ }^{49}$

nen a las dos Coreas, Estados Unidos, China, Japón y Rusia) a las que Corea del Norte ha consentido volver, y que se celebró el pasado febrero en Beijing. El acuerdo allí alcanzado implica que Pyongyang clausurará su principal reactor nuclear en Yongbyon a cambio de combustible o su equivalente en asistencia económica. La decisión norcoreana de clausurar la central nuclear se produjo a cambio de 50,000 toneladas métricas de combustible. Eventualmente, Pyongyang recibirá un millón de toneladas de combustible adicionales, o su equivalente, cuando clausure de manera permanente sus operaciones nucleares. Además se decidió que inspectores internacionales supervisarán el cierre del reactor nuclear norcoreano (véase http://news.bbc.co.uk/hi/spanish/international/newsid_635600 0/6356579.stm). Buena muestra de esta distensión es el tímido camino abierto por las autoridades de Pyongyang y Washington hacia el restablecimiento de relaciones diplomáticas entre EUA y Corea del Norte tras los encuentros que se celebraron a comienzos de marzo en la sede de la ONU en Nueva York. Allí se reunieron el viceministro norcoreano de Asuntos Exteriores, Kim Kye Gwan, acompañado por una misión de siete expertos, y el secretario adjunto de Estado de EUA, Christopher Hill. Por otro lado, el director de la AIEA, Mohamed ElBaradei, acaba de concluir una visita al país (13 y 14 de marzo de 2007) durante la cual las autoridades norcoreanas señalaron que considerarían el volver a ser país miembro de la organización. Asimismo, durante esta visita se han establecido los términos en los que las inspecciones citadas más arriba deberían llevarse a cabo próximamente (http://www.iaea.org/NewsCenter/News/2007/dg_dprk_concludes.html). Por el contrario, la situación en Irán no parece adoptar visos de ir hacia una solución consensuada y pacífica, debido a las reticencias de Ahmadineyad a abandonar sus programas de enriquecimiento de uranio, siempre amparado, según los términos que este dirigente emplea, en su derecho a desarrollar un completo programa nuclear para fines pacíficos. Sin embargo, para los expertos de occidente, los progresos realizados en este campo por Irán podrían llevar al país a producir una bomba atómica en el plazo de tres años.

48 La adopción de esta Resolución se produce, además, en el contexto de tensión internacional que se ha generado tras la detención por las autoridades iraníes de 15 marinos británicos a los que se acusa de invadir aguas territoriales de Irán. El gobierno británico, por el contrario, afirma que los marinos se encontraban navegando en aguas iraquíes.

49 No cabe duda de esto, por cuanto la Resolución precisa el objeto de la misma: "[El Consejo] decidido a hacer efectivas sus decisiones adoptando las medidas adecuadas para persuadir a Irán de que cumpla lo dispuesto en las resoluciones 1696 (2006) y 1737 (2006), así como los requisitos del OIEA, y también para impedir que Irán desarrolle tecnologías estratégicas en apoyo de sus programas nuclear y de misiles, hasta que el Consejo de Seguridad determine que se han alcanzado los objetivos de esas resoluciones"; tampoco en cuanto a los sujetos, dado que esta Resolución detalla en un anexo a la mis- 
En virtud de lo hasta ahora expuesto puede afirmarse que el CSNU se ha adentrado decididamente en la senda de un perfeccionamiento del sistema de sanciones que sin duda ya contribuye, y seguirá haciéndolo, a reducir los efectos nocivos que pueden derivarse de las mismas para sujetos que no son sus destinatarios. Junto a las precisiones y excepciones que ninguna Resolución olvida incluir, también resultan de gran valor otros instrumentos ya referidos, así como la actuación coordinada de todos los agentes implicados en el proceso de aplicación de las medidas concretas (específicamente el propio sistema de Naciones Unidas y, por supuesto, el resto de la comunidad internacional). Antes de pasar al siguiente epígrafe de nuestro trabajo merece la pena hacer una mención especial al procedimiento creado por la breve Resolución 1730, de 19 de diciembre de $2006,{ }^{50}$ en la que el Consejo "destacando que las sanciones son un instrumento importante para el mantenimiento y el restablecimiento de la paz y la seguridad internacionales" y "[m]anteniendo su determinación de asegurar que las sanciones sean cuidadosamente selectivas para apoyar objetivos claros y se apliquen de tal manera que su eficacia compense las posibles consecuencias adversas" se muestra "[d] ecidido a asegurar la existencia de procedimientos justos y claros para incluir a personas y entidades en las listas de sanciones y suprimir sus nombres de ellas, así como para conceder exenciones humanitarias". Para conseguir estos propósitos, el Consejo de Seguridad:

1. Aprueba el procedimiento para la supresión de nombres de las listas que figura como anexo de la presente resolución y pide al secretario general que establezca en la Secretaría... un punto focal para recibir las solicitudes de supresión de nombres de las listas y llevar a cabo las tareas descritas en el

ma, qué entidades (públicas y privadas) y personas participan en actividades nucleares o relacionadas con misiles balísticos, además de establecer limitaciones a los movimientos entre países de otros grupos de personas; y, finalmente, en cuanto a la aplicación temporal de las medidas, establece que el CSNU podrá suspenderlas siempre y cuando verifique que Irán ha suspendido todas las actividades relacionadas con el enriquecimiento y el reprocesamiento, incluidas las de investigación y desarrollo, dejando a salvo la posibilidad de imponer medidas adicionales para persuadir a Irán de que cumpla lo dispuesto en las resoluciones anteriores, si el CSNU lo estima oportuno (véase párrafo 13).

50 Esta Resolución, que recoge claramente los propósitos de refinamiento y perfeccionamiento a los que nos hemos venido refiriendo repetidamente, lleva el sobrenombre de "Cuestiones generales relativas a las sanciones". 
anexo adjunto; y 2. Encarga a los comités de sanciones establecidos por el Consejo de Seguridad... ${ }^{51}$ que revisen sus directrices en consecuencia.

En definitiva, largo y minucioso ha sido y es el trabajo que la comunidad internacional, ya sea individualmente representada en los Estados soberanos o reunida en Naciones Unidas y en el resto de organizaciones de ámbito internacional, tiene que llevar a cabo para conseguir depurar el sistema de seguridad colectivo previsto por el capítulo VII de la CNU, en general, y en particular, el sistema de imposición de medidas recogido en el mismo, el cual, sin implicar el recurso a la fuerza, pretende garantizar la delicada paz y la frágil seguridad, ambas internacionales.

Ha quedado demostrado que esta misión exige realizar algunos cambios y es precisamente esta cuestión, la de las reformas propuestas en el ámbito de la ONU, la que pasamos a estudiar ahora.

\section{El concepto y la emergencia de las sanciones inteligentes en el contexto de las propuestas de reforma}

Los vientos de cambio han soplado fuerte tras el término de la guerra fría y en ese contexto la celebración de la Cumbre del Milenio a inicios del siglo XXI y la llamada Declaración del Milenio de 8 de septiembre de 2000, surgida como resultado de ese encuentro, introdujeron otra vez formalmente la idea de reformar y adaptar el sistema de Naciones Unidas a las nuevas realidades.

De ahí en adelante, y tras hacer suyos la ONU, los Objetivos de Desarrollo del Milenio que se adoptaron previamente en el seno del Comité de Ayuda al Desarrollo de la OCDE, ${ }^{52}$ se han elaborado una serie de informes en que se tratan los distintos aspectos que deben ser modificados en el ámbito general de la ONU y en algunas materias específicas, te-

51 "Incluidos los establecidos en virtud de las resoluciones 1718 (2006), 1636 (2005), 1591 (2005), 1572 (2004), 1533 (2004), 1521 (2005), 1518 (2003), 1267 (1999), 1132 (1997), 918 (1994) y 751 (1992)”.

52 En la página Web de este comité, dentro del recurso electrónico de la propia OCDE, se puede encontrar un vínculo específico relativo a los objetivos de desarrollo del milenio o Millenium Development Goals http://www.oecd.org/department/0,2688, en 2649 34585_1_1_1_1_1,00.html. Asimismo, dentro de la página de Naciones Unidas se contiene un vínculo relativo a los ODM: http://www.un.org/spanish/millenniumgoals/in dex.html. 
niendo como referencia en repetidas ocasiones las directrices marcadas por los ODM.

Los informes y documentos relevantes en relación al tema general de las reformas al funcionamiento y al sistema de Naciones Unidas, para diferenciarlos de otros informes sobre cuestiones más específicas, por ejemplo, el Informe sobre las relaciones entre sociedad civil y Naciones Unidas, ${ }^{53}$ desde 2000 a la fecha, son los siguientes: Informe del SGNU "Nosotros los pueblos: la función de las Naciones Unidas en el siglo XXI", de 27 de marzo de 2000, Doc. A/54/2000; Informe de la Comisión Internacional sobre intervención y la soberanía de los Estados "La responsabilidad de proteger", de diciembre de 2001; Informe del SGNU "Fortalecimiento de las Naciones Unidas: un programa para profundizar el cambio", de 9 de septiembre de 2002, Doc A/57/387; Informe del Grupo de Alto Nivel sobre las amenazas, los desafíos y el cambio "Un mundo más seguro: la responsabilidad que compartimos", de 2 de diciembre de 2004, Doc A/59/565; ${ }^{54}$ Informe del SGNU "Un concepto más amplio de libertad: desarrollo, seguridad y derechos humanos para todos", de 21 de marzo de 2005, Doc A/59/2005; Proyecto de resolución remitido por la Asamblea General, en su 59o. periodo de sesiones, a la Reunión Plenaria de Alto Nivel de la Asamblea General Documento Final de la Cumbre Mundial de 2005 (seguimiento de los resultados de la cumbre del milenio) de 15 de septiembre de 2006, Doc A/60/1.1; Informe del SGNU "Invertir en las Naciones Unidas: en pro del fortalecimiento de la organización en todo el mundo" (seguimiento de los resultados de la Cumbre del Milenio) de 7 de marzo de 2006, Doc A/60/692.

Asimismo, en el marco de la adecuación de Naciones Unidas a un mundo distinto al de 1945 pero en el que los propósitos fijados en aquella época siguen plenamente vigentes, se han creado, también por iniciativa en muchos casos de Kofi Annan, algunos grupos de trabajo o comisiones vinculadas a diversas cuestiones de la organización.

53 Documento A/59/354, llamado Informe del secretario general en respuesta al informe del grupo de personas eminentes encargado de examinar la relación entre las Naciones Unidas y la sociedad civil. Este documento, como todos los demás de Naciones Unidas a los que se hace referencia en este trabajo, es accesible a través del práctico sistema de búsqueda de documentación OSD creado por la ONU. Se accede a él a través del vínculo siguiente: $h t t p: / / d o c u m e n t s . u n . o r g / m o t h e r . a s p$.

54 La ONU ha creado un vínculo electrónico específico para recopilar las actividades de este Grupo de Alto Nivel: http://www.un.org/spanish/secureworld/index.html. 
En relación al tema que nos ocupa, el de las sanciones internacionales en el marco de las reformas del funcionamiento y del sistema de $\mathrm{Na}$ ciones Unidas, los grupos que nos interesan, algunos de los cuales ya han sido traídos a colación, son los siguientes: comités de sanciones (catorce en funcionamiento a marzo de 2007); 5 Comisión de Consolidación de la Paz (creada en diciembre de 2005); ${ }^{56}$ Comité 1540 (creado en virtud del párrafo 4 de la resolución 1540 del Consejo de Seguridad, de 28 de abril de 2004); ${ }^{57}$ Comité contra el Terrorismo (creado en 2001 por la "famosa" Resolución 1373, de 28 de septiembre); ${ }^{58}$ Grupo de Trabajo sobre Cuestiones Generales de las Sanciones (creado en abril de 2000);59 Comité de Sanciones relativas a Al Qaeda y los Talibanes (creado en 1999). ${ }^{60}$

Por su parte, el Consejo de Seguridad, creemos que influido por los desarrollos jurisprudenciales europeos que analizaremos en el apartado siguiente, ha establecido un procedimiento para la supresión de personas de las listas de los comités de sanciones, en su Resolución 1730, de 19 de diciembre de 2006, ya estudiada.

A continuación presentaremos los principales puntos que han sido abordados en este plan de reformas, en relación a las sanciones internacionales, tratando de hacer un contraste entre el tratamiento que le da cada uno y adelantando desde ya una conclusión: en los distintos informes se ofrecen a veces visiones dispares de una misma cuestión.

Específicamente señalaremos, en el contexto de los documentos de reforma que se referirán, las siguientes cuestiones:

a) El rol de las sanciones en el mantenimiento de la paz y la seguridad internacionales.

b) El concepto y la emergencia de las sanciones inteligentes.

c) El cambio necesario en el sistema de las sanciones.

55 Véase supra nota 23.

56 http://www.un.org/spanish/peace/peacebuilding/.

57 El mandato de este comité entronca con el necesario control que ha de hacerse a escala internacional de la producción y proliferación de armas de destrucción masiva, nucleares, químicas y biológicas, y sus sistemas vectores, dado la importante amenaza que suponen para la paz y la seguridad internacionales. El vínculo de este Comité con denominación numérica es el siguiente: http://disarmament2.un.org/committee1540/spanish/ index.html.

58 http://www.un.org/spanish/sc/ctc/.

59 http://www.un.org/spanish/docs/comitesanciones/index.html.

60 http://www.un.org/spanish/docs/comitesanciones/1267/1267Template.htm. 


\section{A. El rol de las sanciones en el mantenimiento de la paz y la seguridad internacionales}

En el Informe del Grupo de Alto Nivel sobre las Amenazas, los Desafíos y el Cambio "Un mundo más seguro: la responsabilidad que compartimos", ${ }^{61}$ en la parte II (La seguridad colectiva y el desafío de la prevención), punto VIII (El papel de las sanciones), concretamente en los párrafos 178-182 se trata la cuestión, y sobre este primer punto que analizamos vemos que el párrafo 178 da una definición y realiza asimismo una defensa de las sanciones internacionales en virtud de su "función intermedia entre la guerra y las palabras".

Por su parte, el Informe del secretario general "Un concepto más amplio de libertad: desarrollo, seguridad y derechos humanos para todos", en su parte III (Libertad para vivir sin temor), punto D (Reducción del riesgo y la prevalencia de la guerra), en los párrafos 106-110 se aborda también la cuestión de las sanciones. En concreto, nos interesa destacar los párrafos 109 y 110 donde también se hace una defensa de las sanciones internacionales como instrumento para la prevención a las amenazas a la paz y la seguridad internacionales en tanto que son un "paso intermedio y necesario entre la guerra y las palabras". Como vemos, reitera la idea del Informe del Grupo de Alto Nivel referida supra y agrega el calificativo de "necesarias". En la misma línea añade que pueden servir para llegar a acuerdos o usarse combinadamente con la fuerza militar, lo que nos parece congruente con la intención de los artículos 41 y 42 de la Carta, en el sentido de que el propósito buscado por la propia Carta es que el CSNU pueda recurrir alternativamente a uno u otro artículo.

En el Proyecto de Resolución remitido por la Asamblea General, en su 59 periodo de sesiones, a la reunión Plenaria de Alto Nivel de la Asamblea General, que corresponde al Documento Final de la Cumbre Mundial de 2005 (seguimiento de los resultados de la Cumbre del Milenio) de 15 de septiembre de 2006, en su "Parte sobre Sanciones" dibuja en los párrafos 106-110 una defensa de las sanciones internacionales como instrumento para el mantenimiento de la paz y la seguridad internacionales, sin recurrir al uso de la fuerza, pero siempre que:

a) Estén en conformidad a la Carta.

b) Sean selectivas. 
c) Contengan objetivos claros.

d) Sean equilibradas y proporcionales entre resultados y consecuencias posibles.

e) Se examinen periódicamente.

f) Y permanezcan en vigor por un tiempo limitado.

Resulta evidente por tanto que en este documento se hace una clara referencia a ellas como herramienta clave para el propósito por el que debe velar el Consejo de Seguridad, precisando en todo caso con claridad bajo qué criterios han de considerarse que sean selectivas.

Se puede entonces ver que en los diversos informes el tema está presente y hay claro consenso sobre que las sanciones internacionales son medidas útiles en el marco del mantenimiento de la paz, sin perjuicio de que el último informe las condiciona bastante como ya hemos dicho.

Por su parte, el Consejo de Seguridad en la repetida Resolución 1730 ha remarcado esta idea de la importancia que tienen las sanciones para el mantenimiento de la paz, haciendo además especial hincapié en el rol que pueden desempeñar para conseguir el "restablecimiento" de la paz y la seguridad internacionales cuando éstas se vean amenazadas o incluso "eliminadas" en regiones específicas de nuestro planeta.

\section{B. El concepto y la emergencia de las sanciones inteligentes} en el contexto de las propuestas de reforma

El Informe del secretario general "Un concepto más amplio de libertad: desarrollo, seguridad y derechos humanos para todos", destaca el rol de las sanciones selectivas (económicas, diplomáticas, restrictivas, etcétera), señalando a su vez que debe mejorarse todo lo posible su proceso de aplicación con el fin de evitar o limitar al máximo los daños a personas y terceros países.

Esto es congruente con la creencia mantenida por la doctrina de que deben cambiarse las sanciones generales que arrastran consigo la idea de "castigo" por un tipo de sanción como la que venimos perfilando, que establezca objetivos específicos mediante los cuales, además, se trata de garantizar que no se dañe a la población civil, sino que, al contrario, lleguen efectivamente a quien tiene que ser el destinatario principal de las mismas. Como dice Bustelo en su análisis crítico en relación a las sanciones a Corea: “¿Acaso se dejará presionar, con este tipo de sanciones, un régimen que dejó morir de hambre a cientos de miles de personas en 
la segunda mitad de los años noventa?". ${ }^{62}$ La pregunta es un claro reflejo de la necesidad de adecuación de las sanciones impuestas.

Por su parte, el Informe del Grupo de Alto Nivel "Un mundo más seguro: la responsabilidad que compartimos" en su parte II (La seguridad colectiva y el desafío de la prevención), punto VIII (El papel de las sanciones), en el párrafo 179, contiene una referencia a las sanciones selectivas y añade que la amenaza que supone su eventual imposición por el CSNU puede actuar como "un medio poderoso de disuasión y prevención".

En el Documento de 15 de septiembre de 2006, en la medida señalada anteriormente, se hace una defensa de las sanciones internacionales como instrumento para el mantenimiento de la paz y la seguridad internacionales, pero siempre que reúnan una serie de condiciones que no significan otra cosa que constituirse en "sanciones selectivas" o "inteligentes". De hecho, entre las condiciones que impone el texto se usa expresamente la idea de "selectivas".

\section{El cambio necesario en el sistema de las sanciones}

El Documento Final de la Cumbre Mundial de 2005 contempla una parte para sanciones y "exhorta", en los términos habitualmente utilizados por los documentos de Naciones Unidas, al CSNU para que con el apoyo del SGNU mejore la aplicación y supervisión sobre las sanciones que el Consejo apruebe imponer.

Por su parte, el Informe del Grupo de Alto Nivel sobre las Amenazas, los Desafíos y el Cambio en su parte II (La seguridad colectiva y el desafío de la prevención), punto VIII (El papel de las sanciones), en los párrafos 180, 181 y 182, recoge propuestas concretas que el Consejo de Seguridad, en el marco de la centralización del sistema de seguridad colectiva, debería asegurar para la aplicación y cumplimiento eficaz de las sanciones. Las propuestas son relativas a: 181.63

a) El propio Consejo de Seguridad, letras a) y e) párrafos $180 \mathrm{y}$

62 Bustelo, P., "La prueba nuclear de Corea del Norte: ¿son suficientes las sanciones del Consejo de Seguridad?", en ARI, Análisis del Real Instituto Elcano, núm. 37, noviembre de 2006, p. 21.

63 Párrafo 180: “a) Cuando el Consejo de Seguridad impusiera un régimen de sanciones (por ejemplo, un embargo de armas) debería, como norma, establecer mecanismos 
b) El secretario general, letras c) y f) párrafo $180 .{ }^{64}$ $182 .{ }^{65}$

c) El Comité de Sanciones, letra b) párrafo 180 y párrafos 181 y

d) Los donantes (Estados), letra d) párrafo 180. ${ }^{66}$

Estas medidas se deben comparar con el análisis que se hace en el mismo Informe punto IV (Los conflictos entre Estados y los conflictos internos), párrafos 74-83, del que surgen:

a) Los propósitos de las sanciones (párrafo 77). ${ }^{67}$

de vigilancia y dotarlos de la autoridad y la capacidad necesarias para realizar investigaciones a fondo de gran calidad. Es necesario consignar créditos presupuestarios adecuados para poner en práctica esos mecanismos"... e) En caso de violaciones verificadas y crónicas de las sanciones, el Consejo de Seguridad debería imponer sanciones secundarias contra los culpables". Párrafo 181: "El Consejo de Seguridad debería seguir tratando de mitigar las consecuencias humanitarias de las sanciones".

64 Párrafo 180: “c) El secretario general debería nombrar a un alto funcionario con recursos de apoyo suficientes, para poder proporcionar al Consejo de Seguridad un análisis de la mejor manera, de imponer sanciones y de ayudar a coordinar su aplicación... f) El secretario general, en consulta con el Consejo de Seguridad, debería asegurar la existencia de un mecanismo de auditoría apropiado para supervisar la administración de las sanciones".

65 Párrafo 180: "b) Se debería encomendar a los comités de sanciones del Consejo de Seguridad la elaboración de mejores directrices y procedimientos de presentación de informes para ayudar a los Estados a aplicar las sanciones y mejorar los procedimientos para mantener listas correctas de personas y entidades sujetas a la aplicación de sanciones selectivas". Párrafo 181: "Los comités de sanciones deberían mejorar los procedimientos para conceder exenciones por motivos humanitarios y evaluar periódicamente los efectos humanitarios de las sanciones". Párrafo 182: “Cuando las sanciones se apliquen a listas de personas o entidades, los comités de sanciones deberían establecer procedimientos para revisar los casos de quienes afirmen que sus nombres se han incluido o mantenido por error en esas listas".

66 Párrafo 180: “d) Los donantes deberían destinar más recursos al fortalecimiento de la capacidad jurídica, administrativa, policial y de control de fronteras de los Estados miembros para aplicar las sanciones".

67 Párrafo 77: "Con el final de la guerra fría, el Consejo de Seguridad comenzó a ocuparse cada vez más activamente de las amenazas internacionales. El número medio de resoluciones aprobadas anualmente por el Consejo pasó de 15 a 60, es decir, de una resolución por mes a una resolución por semana. Antes de 1989, el Consejo había aplicado sanciones en dos oportunidades; desde entonces, lo ha hecho 14 veces, citando una serie cada vez más amplia de propósitos, entre ellos hacer retroceder la agresión, restablecer el gobierno democrático, proteger los derechos humanos, poner fin a la guerra, luchar contra el terrorismo y apoyar acuerdos de paz". 
b) Los resultados (párrafo 78). ${ }^{68}$

c) Las causas del fracaso (recogidas en el párrafo 79), ${ }^{69}$ a saber:

1) Intereses estratégicos de los estados.

2) Falta de claridad respecto al propósito de las sanciones.

3) Cansancio con la aplicación de las sanciones debido a la preocupación por sus consecuencias humanitarias.

4) Apoyo insuficiente por parte de los comités de sanciones respectivos.

5) Capacidad insuficiente de los Estados para aplicar las sanciones. $80) \cdot{ }^{70}$

d) Cambio de sanciones generales a sanciones selectivas (párrafo

e) Críticas y progresos en las sanciones (párrafo 81$).{ }^{71}$

68 Párrafo 78: "Varios de esos regímenes de sanciones surtieron efecto, al menos parcialmente. En algunos casos ayudaron a alcanzar acuerdos negociados. En otros casos, sumados al ejercicio de presión militar, se usaron para debilitar y aislar grupos rebeldes y Estados que se encontraban en abierta violación de las resoluciones del Consejo de Seguridad".

69 Párrafo 79: "Las sanciones fracasaron cuando sus objetivos no se fijaron eficazmente, y cuando el Consejo de Seguridad no las hizo cumplir. El cumplimiento inadecuado es el resultado de los intereses estratégicos de Estados poderosos; la falta de claridad respecto del propósito de las sanciones; el cansancio con la aplicación de las sanciones debido a la preocupación por sus consecuencias humanitarias; un apoyo insuficiente por parte de los comités de sanciones respectivos y una capacidad insuficiente de los Estados para aplicar las sanciones".

70 Párrafo 80: "Como resultado de la creciente preocupación por los efectos humanitarios de las sanciones generales, el Consejo de Seguridad dejó de imponerlas después de los casos del Irak, la ex Yugoslavia y Haití, y pasó a usar exclusivamente sanciones en los ámbitos de las finanzas, la diplomacia, las armas, la aviación, los viajes y los productos básicos, tratando de lograr que afectaran a las partes beligerantes y a las autoridades más directamente responsables de políticas censurables".

71 Párrafo 81: "Una mayor actividad no lleva necesariamente a mayores resultados. No todas las situaciones que merecían la atención del Consejo de Seguridad la recibieron, y no todas las resoluciones del Consejo fueron seguidas de medidas coercitivas eficaces. Sin embargo, dos tendencias del decenio de 1990 indican una creciente eficacia en la solución de los conflictos internacionales. En primer término, con la creciente actividad del Consejo y su disposición a valerse de las facultades que le confiere el capítulo VII de la Carta de las Naciones Unidas, se ha producido un cambio notable en la importancia relativa del uso unilateral de la fuerza y del uso de la fuerza con autorización colectiva. El uso de la fuerza con autorización colectiva tal vez no sea la norma en la actualidad, pero ya no es más una excepción. En segundo lugar cabe mencionar la expectativa surgida recientemente de que el Consejo de Seguridad debe ser el árbitro que decida el 
f) Referencias a EUA y la guerra de Irak y el uso de la fuerza (párrafos 82 y 83$) .72$

Un análisis comparativo del contenido de estos párrafos, insertos en el mismo documento, nos permite advertir que el gran desarrollo que hizo el Grupo de Alto Nivel queda en buena medida reducido a casi nada concreto en el documento político, puesto que creemos que en él debería haberse plasmado un verdadero compromiso en pro de la mejora del sistema de aplicación y ejecución de sanciones, siendo así que sólo se "exhorta" al Consejo de Seguridad, usando este recurrente verbo que no denota precisamente un compromiso de fuerza sino más bien casi una súplica o llamamiento a quien tiene el poder de cambiar las cosas, pero no siempre puede hacerlo.

Pese a ello, la reciente Resolución 1730 es un paso importante en el sentido que apuntamos como el "correcto" por cuanto este documento destaca la necesidad de que las sanciones sean selectivas y crea, además, un procedimiento que va en la línea pretendida de establecer un sistema justo y claro para el ingreso y salida de nombres de las listas que manejan los comités de sanciones y para la concesión de exenciones humani-

uso de la fuerza, lo cual es tal vez el indicador más elocuente de la importancia creciente del papel de las Naciones Unidas en la solución de los conflictos internacionales".

72 Párrafo 82: "Muchas personas creyeron que era perfectamente natural que los Estados Unidos solicitaran el apoyo del Consejo de Seguridad para la guerra en Irak en 2003. Sin embargo, las superpotencias rara vez han solicitado la aprobación del Consejo de Seguridad. El principio de que todos los Estados deberían obtener la autorización del Consejo de Seguridad para usar la fuerza no es algo consagrado por el tiempo. Si así fuese, nuestra fe en él sería mucho mayor. Nuestro análisis parece indicar precisamente lo contrario: se trata de una norma relativamente nueva en proceso de evolución, preciada pero que aún no ha cobrado arraigo". Párrafo 83: "El caso de Irak ha provocado grandes diferencias de opinión. Algunos afirman que el Consejo de Seguridad resultó ineficaz porque no pudo lograr que Irak acatara sus resoluciones. Otros tildan al Consejo de inoperante porque no pudo disuadir de la guerra a los Estados Unidos y a sus aliados. Hay también quienes sugieren que la negativa del Consejo de Seguridad a ceder a las presiones de los Estados Unidos para que legitimara la guerra demuestra su pertinencia y su carácter indispensable: si bien el Consejo no pudo impedir la guerra, proporcionó una norma clara, basada en principios, para evaluar la decisión de ir a la guerra. La multitud de ministros de relaciones exteriores que acudieron a la sala del Consejo de Seguridad durante los debates, y la amplia atención que esos debates suscitaron en el público, sugieren que la decisión de Estados Unidos de presentar la cuestión del uso de la fuerza al Consejo de Seguridad reafirmó la pertinencia y el carácter central de la Carta de las Naciones Unidas". 
tarias, involucrando al secretario general y a los propios comités de sanciones. $^{73}$

Sea como fuere, y a pesar de los esfuerzos que decididamente está llevando a cabo el CSNU en la ansiada labor de refinamiento del sistema de sanciones, no nos cabe duda de que tendremos que esperar todavía un tiempo para ver la utilidad y los beneficios tangibles de tales declaraciones de buenos propósitos que este órgano de Naciones Unidas recoge en todos sus instrumentos. ${ }^{74}$

\section{SANCIONES INTERNACIONALES Y VULNERACIÓN \\ DE DERECHOS HUMANOS. ANÁLISIS JURISPRUDENCIAL EN EL ÁMBITO DEL TJCE}

En el contexto del debate sobre la necesaria reforma de las sanciones del Consejo de Seguridad como hemos expuesto, se intenta reforzar el vínculo entre paz y seguridad internacionales, por un lado, y los derechos humanos, por el otro.

En efecto, "los derechos humanos se convierten en elemento necesario para el mantenimiento, la construcción y la consolidación de la paz". ${ }^{75}$

De ahí que, desde Naciones Unidas, se apueste, entre otras medidas, por incrementar las exenciones a las sanciones del Consejo de Seguridad

73 Esta es también la dirección firmemente seguida por resoluciones posteriores del Consejo de Seguridad, especialmente por la Resolución 1735, así como por las relativas a la no proliferación nuclear, concernientes a la situación en Corea del Norte y en Irán, siendo la más relevante, por ser la última aprobada por el Consejo, la Resolución 1747 a la que ya tuvimos oportunidad de hacer mención supra.

74 Resulta necesario destacar cómo esta labor de refinamiento incluye asimismo un decidido esfuerzo por cubrir todos aquellos flancos que eventualmente pueden afectar a la paz y la seguridad internacionales. En este sentido, la referida Resolución 1735 se detiene a recordar que un terreno tan difícil de rastrear como es el "mundo de la red", Internet, es empleado por los potenciales terroristas como herramienta para coordinar sus actos de terror. Los términos literales de la Resolución son los siguientes: "El Consejo de Seguridad... Expresando su profunda preocupación por el uso criminal que hacen de Internet, Al-Qaida, Osama bin Laden, los talibanes y otros individuos, grupos, empresas y entidades asociados con ellos; en particular, la forma en que se promueven ideologías terroristas". Resulta curioso como en esta "preocupación" del Consejo de Seguridad coincide la Internet, un instrumento nacido en el siglo XX, pero en adelante, perteneciente al XXI, con el término ideología, siendo ésta tan antigua como el hombre.

75 Diez de Velasco, M., Instituciones de derecho internacional público, Madrid, Tecnos, 2005. 
y por controlar la concreción de los sujetos de las mismas, como da cuenta la Resolución 1730, ya citada.

Así también y como hemos referido antes, en su informe "Un mundo más seguro: la responsabilidad que compartimos", el Grupo de Alto Nivel sobre las Amenazas, los Desafíos y el Cambio establece que "los comités de sanciones deberían mejorar los procedimientos para conceder exenciones por motivos humanitarios y evaluar periódicamente los efectos humanitarios de las sanciones" (párrafo 181) y que "cuando las sanciones se apliquen a listas de personas o entidades, los comités de sanciones deberían establecer procedimientos para revisar los casos de quienes afirmen que sus nombres se han incluido o mantenido por error en esas listas" (párrafo 182). De forma más genérica, el Informe del secretario general "Un concepto más amplio de la libertad: desarrollo, seguridad y derechos humanos para todos" prevé que los futuros regímenes de sanciones se estructuren "con sumo cuidado a fin de reducir al mínimo el sufrimiento que se causa a terceros inocentes". También la Asamblea General, en su Documento Final de la Cumbre Mundial 2005, "exhorta" al Consejo de Seguridad a velar por la existencia de procedimientos justos y claros, para la inclusión de personas y entidades en las listas de sanciones y su retirada de ellas, así como para la concesión de exenciones por motivos humanitarios.

En sus esfuerzos por combatir el terrorismo, el Consejo de Seguridad ha aplicado sanciones selectivas o inteligentes contra el régimen de los talibanes y Al Qaeda, precisando el objeto de las medidas, sus sujetos, así como el tiempo de duración de las mismas. Se han ampliado las funciones de los comités de sanciones y se han creado mecanismos complementarios para la gestión de las sanciones. No obstante, dichas medidas siguen planteando dificultades.

Se pone en cuestión la legalidad de las decisiones del Consejo y el problema de su control; en concreto, en casos de posibles violaciones de derechos fundamentales. ${ }^{76}$

Podemos observar estas cuestiones en las recientes sentencias, de 21 de septiembre de 2005, del Tribunal de Primera Instancia de las Comuni-

76 "Si el Consejo de Seguridad continúa actuando como una agencia administrativa que afecta directamente a los derechos humanos, deben introducirse reformas para una mejor protección de dichos derechos". Tomuschat, C., Case Law: Case T-306/01; Case T-315/01, Common Market Law Review 43: 537-551, 2006, p. 551. 
dades Europeas: ${ }^{77}$ sentencia T-306/01 (Ahmed Ali Yusuf y Al Barakaat International Foundation/Consejo de la Unión Europea y Comisión de las Comunidades Europeas) y sentencia T-315/01 (Yassin Abdullah Kadi/Consejo de la Unión Europea y Comisión de las Comunidades Europeas). En ambas, la Comunidad Europea se declara competente, en cumplimiento de una serie de resoluciones del Consejo de Seguridad, para imponer la congelación de fondos de particulares en el contexto de la lucha contra el terrorismo internacional. Las sentencias confirman que, aunque gran parte de dichas medidas no están sometidas al control de los Tribunales por venir exigidas por el Consejo de Seguridad, no violan los derechos fundamentales de los demandantes.

A continuación, revisaremos, en primer lugar, las alegaciones de los demandantes en los citados casos; para pasar después a considerar las cuestiones más relevantes resueltas por el Tribunal desde la perspectiva

77 Aunque nuestro estudio se basará en las citadas sentencias; como ejemplo paradigmático de los posibles riesgos para los derechos humanos que pueden entrañar las sanciones del Consejo de Seguridad, existen otras sentencias interesantes del Tribunal de Justicia de las Comunidades Europeas, tales como la de 27 de febrero de 2007 en el asunto Gestoras pro Amnistía y otros contra el Consejo de la Unión Europea (http://curia.europa.eu/jurisp/cgibin/form.pl? lang $=e s \& n e w f o r m=n e w f o r m \& a l l j u r=$ alljur\&jurcdj $=j u r c d j$ $\& j u r t p i=j u r t p i \& j u r t f p=j u r t f p \&$ alldocrec $=$ alldocrec $\&$ doc $j=d o c j \&$ docor $=$ docor $\&$ doco $p=d$ ocop $\&$ docav $=$ docav\&docsom $=$ docsom $\&$ docinf $=$ docinf\&alldocnorec $=$ alldocnorec $\&$ docn $o j=$ docnoj\&docnoor $=$ docnoor\&typeord $=$ ALLTYP\&allcommjo $=$ allcommjo \&affint $=$ affint $\&$ affclose $=$ affclose $\&$ numaff $=\&$ ddatefs $=\&$ mdatefs $=\& y$ datefs $=\&$ ddatefe $=\&$ mdatefe $=\& y d$ atefe $=\&$ nomusuel $=$ Gestoras + pro + amnist $\% C 3 \%$ ADa\&domaine $=\&$ mots $=\&$ resmax $=100$ $\&$ Submit=Buscar). La del 1o. de febrero de 2007 en el asunto José María Sisón contra el Consejo de la Unión Europea (http://curia.europa.eu/jurisp/cgibin/form.pl?lang=es\& newform $=$ newform \&Submit $=$ Buscar\&alljur $=$ alljur\&jurcdj=jurcdj\&jurtpi=jurti\&jurtfp= jurtfp \&alldocrec $=$ alldocrec $\&$ docj $=$ docj\&docor $=$ docor $\&$ docop $=$ docop $\&$ docav $=$ docav $\& d$ ocsom $=$ docsom $\&$ docinf $=$ docinf $\&$ alldocnorec $=$ alldocnorec $\&$ docnoj $=$ docnoj $\&$ docnoor $=$ docnoor\&typeord $=$ ALLTYP\&allcommjo $=$ allcommjo \&affint $=$ affint\&affclose $=$ affcloe\&nu maff $=\&$ ddatefs $=\&$ mdatefs $=\& y$ datefs $=\&$ ddatefe $=\&$ mdatefe $=\& y$ datefe $=\&$ nomusuel $=$ sis $\%$ $C 3 \%$ Bn \&domaine $=\&$ mots $=\&$ resmax $=100$ ) o la de 12 de diciembre de 2006 en el asunto Organización Mujahedin del Pueblo de Irán contra el Consejo de la Unión Europea (http://curia.europa.eu/jurisp/cgibin/form.pl?lang=es\&newform=newform\&alljur $=$ alljur $\& j u r c d j=j u r c d j \& j u r t p i=j u r t p i \& j u r t f p=j u r t f p \&$ alldocrec $=$ alldocrec $\& d o c j=d o c j \& d o c o r=d$ ocor\&docop $=$ docop $\&$ docav $=$ docav\&docsom $=$ docsom $\&$ docinf $=$ docinf\&alldocnorec $=$ all docnorec $\&$ docnoj $=$ docnoj\&docnoor $=$ docnoor $\&$ typeord $=A L L T Y P \&$ allcommjo $=$ allcomm $o \&$ affint $=$ affint\&affclose $=$ affclose \&numaff $=T) 228 \% 2 F 02 \&$ ddatefs $=\&$ mdatefs $=$ \&ydatefs $=\&$ ddatefe $=\&$ mdatefe $=\& y$ datefe $=\&$ nomusuel $=\&$ domaine $=\&$ mots $=\&$ resmax $=100 \&$ Sub mit=Buscar). 
de las relaciones entre las sanciones impuestas y la protección de los derechos fundamentales.

1. Alegaciones de los demandantes en los casos Yusuf, Al Barakaat y Kadi

Las pretensiones de los demandantes en los asuntos T-306/01 y $\mathrm{T}-315 / 01$ son coincidentes en cuanto a que alegan, ante el Tribunal de Primera Instancia de las Comunidades Europeas, la violación de sus derechos fundamentales por determinados reglamentos comunitarios, adoptados en ejecución de resoluciones del Consejo de Seguridad. Analizaremos dichas demandas por separado para observar sus particularidades.

En el primer caso, T-306/01, los demandantes, Ahmed Ali Yusuf y al Barakaat International Foundation, son un nacional sueco de origen somalí y una asociación sin ánimo de lucro que, entre otras actividades, presta apoyo a refugiados y ayuda a realizar transacciones monetarias entre personas que residen en Suecia y personas que residen en Somalia. ${ }^{78}$ Los demandantes alegan que, con el Reglamento núm. 467/2001, que congela sus fondos y prohíbe que se pongan recursos financieros a su disposición, el Consejo se ha excedido en el ejercicio de sus competencias. Estiman que el Consejo no está facultado para imponer sanciones contra organizaciones o individuos concretos y ha incurrido en desviación de poder. Los demandantes sostienen que ni el Consejo ni la Comisión han verificado los motivos por los que el Comité de Sanciones contra los Talibanes los incluyó en la lista y que tampoco se les ha dado la oportunidad de conocer los informes que han servido de base para su inclusión en la lista, ni de presentar observaciones sobre ellos. Así pues, consideran que se les han impuesto graves sanciones sin darles la posibilidad de defenderse. De este modo, los demandantes alegan que se han violado los principios jurídicos fundamentales en materia de garantías procesales. Añaden también que el Reglamento núm. 2199/2001 adolece de vicios sustanciales en relación con la necesidad de que cada caso haya sido objeto de comprobación y que existen razones de peso para dudar que sea adecuado imponerles sanciones.

78 En este mismo asunto, desistieron de sus recursos ante el Tribunal de Primera Instancia otros dos demandantes suecos de origen somalí, los señores Aden y Alí, que mediante el procedimiento de revisión ante el Comité de Sanciones a través de su Estado, consiguieron desbloquear sus fondos. 
En segundo lugar, en la sentencia T-315/01, Kadi, ciudadano de Arabia Saudí con importantes intereses financieros en la Unión Europea, impugna la validez del Reglamento núm. 2062/2001 que modifica por tercera vez el Reglamento núm. 467/2001 del Consejo por el que se prohíbe la exportación de determinadas mercancías y servicios a Afganistán, se refuerza la prohibición de vuelos y se amplía la congelación de capitales y otros recursos financieros de los talibanes de Afganistán y por el que se deroga el Reglamento núm. 337/2000, en la medida en que incluyó el nombre del demandante en el Anexo I del Reglamento núm. 467/2001 del Consejo. En virtud del artículo 2o., apartado 1, de este último, todos los fondos pertenecientes a las personas designadas por el Comité de sanciones contra los talibanes de las Naciones Unidas deben ser congelados. En apoyo de sus pretensiones, el demandante alega que las medidas de que se trata: vulneran su derecho de propiedad, que se encuentra protegido como derecho fundamental del ordenamiento jurídico comunitario; facultan al Consejo y a la Comisión, violando el derecho a un proceso justo, para congelar sus activos y mantenerlos inmovilizados sin otorgarle la posibilidad de ser oído por dichas autoridades con el objeto de convencerles de que liberen sus activos; $y$, por último, no le permiten, vulnerando con ello el principio de tutela judicial efectiva del derecho comunitario, la interposición de recurso judicial alguno con el fin de impugnar su inclusión en la lista y obtener que un órgano jurisdiccional realice una valoración independiente de la base probatoria que demuestra la conculcación de sus derechos.

\section{Decisión del Tribunal de Primera Instancia de las Comunidades Europeas}

Tanto en el asunto T-306/01 como en el asunto T-315/01, el Tribunal de Primera Instancia desestimó los recursos de los demandantes por infundados, condenándolos en costas. Analizaremos de forma conjunta las cuestiones más relevantes resueltas por el Tribunal.

\section{A. Competencia del Consejo para imponer sanciones a particulares}

Los artículos 301 y 60 del Tratado de la Comunidad Europea $(\mathrm{TCE})^{79}$ permiten que el Consejo imponga sanciones económicas y fi-

79 Artículo 301, TCE: “Cuando una posición común o una acción común, adoptadas con arreglo a las disposiciones del Tratado de la Unión Europea relativas a la política ex- 
nancieras a países terceros cuando una posición común adoptada por la Unión Europea en el marco de la política exterior y de seguridad común (PESC) así lo decida. En el tema de las sanciones, la práctica de las instituciones comunitarias ha evolucionado en el mismo sentido que la de Naciones Unidas; es decir, sustituyendo las clásicas sanciones de embargo comercial generalizado contra un país, por otras medidas más específicas y selectivas dirigidas al régimen de que se trate y a sus responsables. Las nuevas sanciones inteligentes son compatibles, según el Tribunal de Primera Instancia, "tanto por razones de eficacia como por consideraciones humanitarias", con los citados artículos.

Dando un paso más, el Tribunal considera que, igual que resulta legítimo que las sanciones económicas o financieras se apliquen específicamente a los dirigentes de un país tercero, en vez de al país como tal, también es necesario que tales sanciones puedan aplicarse a los individuos y entidades asociados con dichos dirigentes o controlados directa o indirectamente por ellos, con independencia del lugar en que se encuentren. Concluye, por tanto, que el Consejo es competente para imponer a los particulares sanciones económicas y financieras, como la congelación de fondos, en el contexto de la lucha contra el terrorismo internacional.

\section{B. Primacía del derecho de Naciones Unidas sobre el derecho comunitario}

El Tribunal de Primera Instancia reconoce que las obligaciones que la Carta de las Naciones Unidas impone a los Estados miembros de la ONU prevalecen sobre todas las disposiciones de derecho interno, con base en los principios del derecho internacional consuetudinario, y sobre todas las disposiciones de derecho internacional convencional, con base

terior y de seguridad común, impliquen una acción de la Comunidad para interrumpir o reducir parcialmente o en su totalidad las relaciones económicas con uno o varios terceros países, el Consejo adoptará las medidas urgentes necesarias. El Consejo decidirá por mayoría cualificada a propuesta de la Comisión". Artículo 60.1, TCE: "Si, en los casos contemplados en el artículo 301, se considerare necesaria una acción de la Comunidad, el Consejo, con arreglo al procedimiento previsto en el artículo 301, podrá tomar las medidas urgentes que sean necesarias sobre movimientos de capitales y sobre pagos respecto de los terceros países de que se trate". 
en el artículo 103 de la Carta. ${ }^{80}$ Las decisiones contenidas en las resoluciones del Consejo de Seguridad disfrutan de la misma primacía, con arreglo a lo dispuesto en el artículo 25 de la Carta. ${ }^{81}$

Respecto a las relaciones entre las obligaciones que la Carta impone a los Estados y las que les impone el derecho comunitario, el artículo 307, TCE, establece que "las disposiciones del presente Tratado no afectarán a los derechos y obligaciones que resulten de convenios celebrados con anterioridad al 1o. de enero de 1958 o, para los Estados que se hayan adherido, con anterioridad a la fecha de su adhesión, entre uno o varios Estados miembros, por una parte, y uno o varios terceros Estados, por otra". En efecto, en el caso Levy, ${ }^{82}$ el Tribunal declaró que el juez nacional tenía la obligación de garantizar el cumplimiento de una directiva comunitaria, dejando inaplicada cualquier disposición contraria de la legislación nacional, salvo si la aplicación de dicha disposición fuera necesaria para garantizar el cumplimiento por el Estado miembro de que se trata de obligaciones resultantes de un Convenio celebrado con Estados terceros antes de la entrada en vigor del TCE.

El Tribunal, en las sentencias que nos ocupan, concluye que la Comunidad, al no ser miembro de la Organización de Naciones Unidas, no está por tanto vinculada directamente por la Carta de Naciones Unidas. No obstante, en la medida en que asume, con arreglo a su propio Tratado constitutivo, competencias anteriormente ejercidas por los Estados miembros en el ámbito de aplicación de la Carta de las Naciones Unidas, las disposiciones de dicha Carta le son vinculantes. Completa este razonamiento añadiendo que la Comunidad no puede violar las obligaciones que la Carta impone a sus Estados miembros, ni obstaculizar la ejecución de las mismas y que se encuentra obligada a adoptar todas las disposiciones necesarias para permitir que sus Estados miembros cumplan dichas obligaciones. En efecto, como establecen González Campos, Sánchez

80 Artículo 103, Carta NU: "En caso de conflicto entre las obligaciones contraídas por los miembros de las Naciones Unidas en virtud de la presente Carta y sus obligaciones contraídas en virtud de cualquier otro convenio internacional, prevalecerán las obligaciones impuestas por la presente Carta".

81 Artículo 25, Carta NU: "Los miembros de las Naciones Unidas convienen en aceptar y cumplir las decisiones del Consejo de Seguridad de acuerdo con esta carta".

82 Asunto C-158/91, sentencia del Tribunal de Justicia de las Comunidades Europeas de 2 de agosto de 1993. 
Rodríguez y Andrés Sáenz de Santa María, ${ }^{83}$ la base jurídica de las resoluciones del Consejo de Seguridad en el derecho comunitario se halla en los acuerdos de los Estados miembros adoptados en el marco del pilar de cooperación intergubernamental de la política exterior y de seguridad común, así como en los artículos 301 y 307, TCE.

\section{Amplitud del control de legalidad que corresponde ejercer al Tribunal de Primera Instancia}

El Tribunal establece que el Reglamento impugnado se limita a aplicar, a nivel comunitario, ciertas decisiones del Consejo de Seguridad. Éstas, en principio, no están sometidas al control jurisdiccional del Tribunal de Primera Instancia, el cual no se encuentra autorizado a cuestionar, ni siquiera de modo incidental, la legalidad de las mismas desde el punto de vista del derecho comunitario. No obstante, lo que sí puede controlar el Tribunal de Primera Instancia de modo incidental es la legalidad de las resoluciones del Consejo de Seguridad controvertidas desde el punto de vista del ius cogens. El ius cogens internacional, como señala Remiro Brotóns, "ha de apreciarse en un caso concreto, en un momento dado, por un juez determinado". 84

En el caso en cuestión, el Tribunal de Primera Instancia identifica con normas de ius cogens todas las normas para la protección universal de los derechos fundamentales de las personas, hipótesis discutible que el Tribunal no resuelve. Examinará, por tanto, las alegaciones de los demandantes utilizando como único criterio de referencia el ius cogens, en dicha acepción.

\section{Supuestas violaciones de los derechos fundamentales de los demandantes}

En primer lugar, el Tribunal se pronuncia respecto a la pretendida vulneración del derecho de propiedad de los demandantes. Establece que la congelación de fondos persigue un objetivo de interés general para la

83 González Campos, J. D. et al., op. cit., nota 12, pp. 415 y 416.

84 Remiro Brotóns, A. et al., Derecho internacional, Madrid, McGraw-Hill, 1997, p. 28. Aunque para este trabajo se ha consultado esta edición, resulta obligado señalar que ha aparecido una nueva recientemente en otra editorial, véase $i d$. et al., Derecho internacional, Madrid, Tirant lo Blanch, 2007. 
comunidad internacional, como es la lucha contra el terrorismo internacional, y que, a diferencia de la confiscación, no afecta a la propia esencia del derecho de propiedad de los interesados sobre sus activos financieros, sino únicamente a la utilización de los mismos. Además, recuerda que la congelación de fondos no se aplica a los fondos necesarios para sufragar gastos básicos y que las resoluciones del Consejo de Seguridad controvertidas establecen un mecanismo de revisión periódica del régimen de sanciones y un procedimiento que permite a los interesados someter su caso para revisión al Comité de Sanciones, a través del Estado miembro del que son nacionales o en el que residen. Con base en lo expuesto, el Tribunal desestima las alegaciones de los demandantes por considerar que no existe violación arbitraria, inadecuada o desproporcionada del derecho de propiedad.

En segundo lugar, respecto al derecho de defensa de los demandantes, el Tribunal comienza estimando que las instituciones comunitarias (en concreto, el Consejo) no están obligadas a oír a los interesados, ya que no disponen de margen de apreciación alguno en la aplicación de las sanciones decididas por el Consejo de Seguridad. En efecto, tanto el fondo de las medidas de que se trata como los mecanismos de revisión de las mismas son competencia exclusiva del Consejo de Seguridad y de su Comité de Sanciones. En cuanto al derecho de los interesados a ser oídos personalmente por el Comité de Sanciones, el Tribunal considera que no puede ser exigido con base en ninguna norma de ius cogens. De hecho, establece que, desde el momento en que el Consejo de Seguridad estima que existen razones relacionadas con la seguridad de la comunidad internacional que se oponen a ello, el respeto de los derechos fundamentales no exige que se les comuniquen a los interesados los hechos y pruebas utilizados en su contra. Añade que éstos pueden dirigirse en todo momento al Comité de Sanciones, a través de sus autoridades nacionales, a fin de obtener que se retire su nombre de la lista de personas a quienes se aplican las sanciones, o bien ciertas excepciones a la congelación de sus fondos. El Tribunal llega a afirmar que, al no estar reconocido el derecho directo de los interesados a ser oídos por el Comité de Sanciones, dichas personas dependen exclusivamente de la protección diplomática otorgada por los Estados a sus ciudadanos (protección que, omite recordarlo, es discrecional).

Por último, el Tribunal se pronuncia sobre el derecho a un control jurisdiccional efectivo. Establece que no le corresponde controlar indirec- 
tamente la conformidad de las resoluciones del Consejo de Seguridad con los derechos fundamentales protegidos por el ordenamiento jurídico comunitario, ni verificar la inexistencia de error en la apreciación de los hechos y pruebas que el Consejo de Seguridad tuvo en cuenta para adoptar las medidas decididas por él, y ni siquiera controlar indirectamente la oportunidad o la proporcionalidad de tales medidas. Los demandantes, por tanto, dentro de dichos límites, no disponen de ninguna vía de recurso ante los tribunales, al no existir un tribunal internacional encargado de juzgar los recursos interpuestos contra las decisiones del Comité de Sanciones. A pesar de reconocer que existe una laguna en la protección judicial de los demandantes, el Tribunal considera que ésta no es en sí contraria al ius cogens y que el derecho de acceso a los tribunales no constituye un derecho absoluto, pudiendo suspenderse en situaciones excepcionales y quedando también limitado por ciertas restricciones. En este asunto, el derecho de acceso a los tribunales de los demandantes, choca con la inmunidad de jurisdicción de que disfrutan las resoluciones del Consejo de Seguridad.

\section{CONCLUSIONES}

Las actuaciones del CSNU han sido repetidamente cuestionadas en diversos ámbitos desde hace muchos años, especialmente y con mayor intensidad tras el "renacer" de su actividad que el fin de la guerra fría trajo consigo.

En su papel como garante de la paz y la seguridad internacionales parece extender su actuación a mucho más de aquello que originalmente le asigna el marco legal al cual debe ajustar su actividad, esto es, la Carta de las Naciones Unidas. Este acaparamiento de competencias, junto con la tendencia del Consejo a apreciar su misión en función de los intereses en juego y criterios políticos en el conflicto en cuestión, han "acentuado la reivindicación de cumplir y respetar la Carta hasta sus últimas consecuencias, incluidas las posibles formas de control que permite en su estado actual" y han "suscitado posibles reformas en la Carta entre las que no se descarta una mayor delimitación de los poderes del Consejo". ${ }^{85}$

85 López-Jacoiste Díaz, M. E., Actualidad del Consejo de Seguridad de las Naciones Unidas. La legalidad de sus decisiones y el problema de su control, Madrid, Civitas Ediciones, 2003, pp. 168 y 169. 
En ese marco, las llamadas sanciones internacionales y sus efectos en los derechos humanos de muchas personas, sirven de buen ejemplo para analizar la "legalidad" de la actuación del Consejo de Seguridad.

En el plano general de Naciones Unidas la cuestión no ha pasado inadvertida para los distintos actores involucrados en el proceso de mejorar la organización, lo que ha quedado reflejado en varios de los informes que buscan establecer marcos y pautas de trabajo que orienten los cambios que es necesario introducir.

Estos informes han arrojado en algunos casos interesantes luces sobre por qué han fallado en ciertos casos las sanciones y qué es necesario cambiar para mejorar su aplicación. Lamentablemente, al depender en buena parte los cambios de la voluntad política de los principales actores estatales de la organización, el resultado es que según de quien emanen los diversos informes, éstos ofrecen a veces distintas visiones sobre una misma cuestión y en aquellos que tienen un peso un poco mayor que el meramente doctrinario, los compromisos que parece necesario adoptar no resaltan en importancia como deberían.

Asimismo, tal como hemos explicado, las sanciones están generando diversos efectos en la vida de miles de personas que no necesariamente son quienes deberían ser los destinatarios de estas medidas. Casos paradigmáticos se han producido a propósito de los talibanes y sus reclamaciones judiciales, como ha quedado evidenciado tras el estudio de las sentencias del TJCE que hemos reseñado, debiendo señalarse además que la misión de control de los actos de talibanes que pueden ser potencialmente peligrosos es una de las que más esfuerzos y actividad requiere del Consejo.

En cuanto a los asuntos procesales citados, el Tribunal de Primera Instancia desestimó los recursos de los demandantes por infundados. Con ello, lo que el Tribunal viene a reconocer en las sentencias analizadas es que todos los derechos humanos admiten excepciones y que, por tanto, no ha habido vulneración alguna porque ha primado, sobre los intereses de los demandantes, el interés general esencial en el mantenimiento de la paz y la seguridad internacionales frente a una amenaza claramente identificada por el Consejo de Seguridad. No obstante, al tratar de justificar su "tesis", el Tribunal parece acabar demostrando todo lo contrario: que efectivamente se han violado derechos fundamentales de los interesados. Como establece C. Tomuschat, si bien la sociedad debe ser protegida de amenazas terroristas, los derechos e intereses de las personas que son el 
centro de atención de los servicios de inteligencia no pueden ser sacrificados arbitrariamente. ${ }^{86}$

Sin embargo, el Tribunal deja el derecho de defensa en las discrecionales manos de la protección diplomática, considerando que no es necesario que se comuniquen a los demandantes los hechos o pruebas utilizados en su contra e incluso asume una laguna en la protección judicial de los demandantes al no disponer estos de ninguna vía de recurso ante los Tribunales.

El 17 de noviembre de 2005, se han interpuesto ante el Tribunal de Justicia de las Comunidades Europeas sendos recursos de casación, solicitando la anulación de las resoluciones del Tribunal en Primera Instancia de 21 de septiembre de 2005.

Analizados estos casos, se nos plantea la cuestión de si estamos ante uno de los panoramas inciertos y abusivos que preveía la profesora Andrés Sáenz de Santa María, al reconocer que "el carácter de órgano político del Consejo y los precedentes de instrumentalización del mismo hacen inevitable la duda de si estaremos ante una tendencia consolidada o si por el contrario el futuro puede depararnos nuevos casos de uso abusivo de las sanciones, como ocurrió con Irak". ${ }^{87}$

Efectivamente, tal como establece M. Craven, ${ }^{88}$ en la práctica, los argumentos humanitarios actúan menos como una limitación a la capacidad del Consejo de Seguridad para imponer sanciones, y más como un vehículo para justificar su uso.

Habrá que esperar a las sentencias del Tribunal de Justicia de las Comunidades Europeas, resolviendo en casación los asuntos citados, para pronunciarse definitivamente al respecto y habrá que esperar que los estados más poderosos asuman que es necesaria una mayor regulación del régimen de las sanciones y estén dispuestos a ello.

De todos modos, nos parece claro que frente a los problemas que han surgido en la práctica y frente a los "encuentros" entre el derecho que aplica Naciones Unidas y los derechos humanos, siempre deberá privilegiarse cualquier solución que sea favorable a estos últimos.

86 Tomuschat, C., op. cit., nota 76, p. 539.

87 Andrés Sáenz de Santa María, P., "Derecho, moral y eficacia en la práctica de sanciones del Consejo de Seguridad", Soberanía del Estado y derecho internacional. Homenaje al profesor Juan Antonio Carrillo Salcedo, Sevilla-Málaga, Servicios de Publicaciones de las Universidades de Córdoba, 2005, p. 176.

88 Craven, M., op. cit., nota 3, p. 60. 